\title{
Dry fractionation of olive pomace for the development of food packaging biocomposites
}

\author{
Sarah Lammi ${ }^{\mathrm{a}, \mathrm{b}}$, Nicolas Le Moigne ${ }^{\mathrm{c}}$, Djamel Djenane ${ }^{\mathrm{b}}$, Nathalie Gontard ${ }^{\mathrm{a}}$, \\ Hélène Angellier-Coussy ${ }^{\mathrm{a}, *}$ \\ a JRU IATE 1208-CIRAD/INRA/Montpellier SupAgro/University of Montpelier, 2 Place Pierre Viala, F-34060 Montpellier, France \\ ${ }^{\mathrm{b}}$ Laboratory of Food Quality and Food Safety, Department of Agronomic Sciences, University of Mouloud MAMMERI, BP 17, 15000 Tizi-Ouzou, Algeria \\ ${ }^{\mathrm{c}}$ C2MA, IMT Mines Alès, Université Montpellier, 6 Avenue de Clavières, 30319 Alès Cedex, France
}

\begin{abstract}
A B S T R A C T
Three lignocellulosic fractions with contrasted properties were produced by dry fractionation of olive pomace (OP): a stone-rich fraction (SF) rich in cellulose and having high polarity, a pulp-rich fraction (PF) richer in lignin and less polar, and a crude pomace fraction (CF) with intermediate properties. These fractions were used as fillers in two thermoplastic matrices, i.e. polyprolylene (PP) and polyhydroxybutyrate-co-valerate (PHBV). Tensile tests showed a decrease of both the stress and the elongation at break for all biocomposites, while the Young's modulus was not significantly affected. At low filler contents, no effect of filler composition was ob-served whereas at high filler content (30 wt\%), the decrease in the stress at break was less pronounced for PHBV-PF, with respective reduction values of $36 \%, 65 \%$ and up to $78 \%$ for PHBV-PF (30\%), PHBV-CF (30\%)and PHBV-SF (30\%) composites, as compared to the neat PHBV. The elongation at break also greatly decreased according to the filler content. The highest reduction was recorded in the case of SF fillers, with a reduction of $74 \%$ for PHBV-SF composites. Mechanical properties were better preserved in the case of the PF filler due to better interfacial adhesion towards the matrices, as revealed by work of adhesion calculations, SEM observations and mechanical modelling. Water vapour permeability (WVP) of both matrices was increased in presence of both SF and CF fillers, while oxygen permeability was not significantly affected by the fillers. As an example, WVP increased from $0.9 \pm 0.1 \times 10$

${ }^{-12} \mathrm{~mol} \mathrm{~m}^{-1} \mathrm{~s}^{-1} \mathrm{~Pa}^{-1}$ for the neat PHBV up to $15.1 \pm 2.6 \times 10^{-12} \mathrm{~mol} \mathrm{~m}^{-1} \mathrm{~s}^{-1} \mathrm{~Pa}^{-1}$ for PHBV-CF (30\%). This supports a promising use of SF/CF fractions in sustainable biocomposites packaging for respiring food products, the PF-based formulations being more appropriate for non-respiring and water sensitive products. Our results demonstrated that the conditioning of lignocellulosic biomass by dry fractionation is im-portant for the control of bio-based fillers properties and the resulting functionalities of biocomposites. Besides, the PP-based composites developed in this study allow reducing costs and dependence to fossil resources, while PHBV-based biocomposites also have the advantage of being fully bio-based and biodegradable.
\end{abstract}

Keywords:

Olive pomace

Dry fractionation

Biocomposites

Mechanical properties

Barrier properties

Food packaging

\section{Introduction}

Food packaging is the sector consuming most plastics, with about $40 \%$ of the global demand worldwide. Polypropylene (PP) is at the head with more than $19 \%$ of usages (Plastics-the Facts, 2016. In view of reducing food waste while limiting the harmful effects of petrochemical-derived plastic residues on the environment, the conception of fully bio-based and biodegradable packaging materials having tailored mass transfer properties constitutes one alternative to overcome these issues (Angellier-Coussy et al., 2013). Among them, polyhydroxyalkanoates (PHA) are bacterially-derived thermoplastic polymers that can be produced from renewable resources, including solid or liquid agro-residues and municipal wastes. They have gained major importance worldwide due to their macromolecular structure diversity and close properties to conventional plastics that make them highly competitive with respect to PP. The copolyester polyhydroxy-(3-butyrate-co-3-valerate) (PHBV) is one of the best characterized PHA (Reddy et al., 2003). Besides its higher price as compared to conventional plastics, the main limitation restricting its commercial application at a large scale is its barrier properties which are too high to fit respiring products needs such as fruits and vegetable (Berthet et al., 2016).

One environmentally virtuous strategy to modulate PHBV barrier properties while reducing the final cost of materials is to mix it with low cost lignocellulosic fillers obtained from food industry solid by-products

\footnotetext{
* Corresponding author

E-mail address: helene.coussy@umontpellier.fr (H. Angellier-Coussy).
} 
(Berthet et al., 2015, 2016). Olive pomace (OP), which is the solid lignocellulosic residue of olive oil extraction, is a very good candidate for this purpose due to its very high availability and low cost. Its production is mainly concentrated in Mediterranean area, but the emergence of new producer countries leads to an intense accumulation of OP that is estimated to reach 2,881,500 tons/year worldwide (Ravindran and Jaiswal, 2016). Olive pomace is a mixture of residual skin, pulp and fragments of the crushed stone. Until now, only the part corresponding to the olive stone has been valorized in the field of biocomposites by combining it either with synthetic polymers such as unsaturated polyesters (Gharbiet al., 2014), polyvinyl chloride (PVC) (Djidjelli et al., 2007), PP (Naghmouchi et al., 2015; Siracusa et al., 2001), or biodegradable polymers such as wheat gluten (Hammoui et al., 2015), polylactic acid (PLA) (Koutsomitopoulou et al., 2014) and PHBV (Hassaini et al., 2017). Neither the whole crude OP nor the olive pulp has been yet exploited in this way. In addition, all these studies mainly focused on mechanical and thermal properties of the resulting biocomposites. Only Hassaini et al. (2017) were interested about oxygen and water vapour permeability of these biocomposites after chemical treatment of the stone-based filler to improve its affinity toward the PHBV matrix. It is also worth noting that OP is often exclusively treated using wet processes consuming a large amount of water and chemicals (hexane and/or acetone) in order to separate the pulp from the stone, thus generating pollutant and toxic effluents. In the perspective to reduce the harmful environmental impact of OP by its sustainable valorization, dry fractionation combining grinding and sorting processes (electrostatic separation, friction or sieving) has been recently demonstrated to be a sustainable technology to produce fillers from crude olive pomace. It was shown that friction in a ball mill was the most adapted mechanical treatment to produce pulp-rich and stone-rich powders with high yield and purity, and contrasted biochemical composition and polarity (Lammi et al., 2018).

In this context, the present work aims at exploring the potential use of the two main parts of olive pomace, i.e. the stone and the pulp, as fillers in biocomposites and to compare it to that of the crude OP. For this purpose, pulp-rich and stone-rich fractions with contrasted biochemical composition and physico-chemical surface properties were produced by dry fractionation and used as fillers in a petroleum based polymer matrix, polypropylene (PP), and a bio-based polymer matrix, polyhydroxy-butyrate-co-valerate (PHBV). Biocomposites with increasing filler contents were prepared by melt compounding and thermo-compression and their optical (color), microstructural, thermal, mechanical (tensile) and barrier (water vapour and oxygen permeability) properties were characterized. Changes in material functional properties are discussed in relation to the intrinsic characteristics of olive pomace-based fillers, including their color, density, size, morphology, biochemical composition, thermal stability and surface free energy. Special attention is given to understand the impact of the composition of OP-based fillers and especially their physico-chemical affinity with the thermoplastic matrices on biocomposites functional properties. Finally, their possible application in the food packaging sector was discussed.

\section{Materials and methods}

\subsection{Raw materials}

Algerian crude olive pomace (OP) of the Chemlal variety was kindly provided in December 2016 by local olive producers in the region of Azeffoun (Tizi-Ouzou) located in north-central of Algeria. OP was stored in a cold room at $4{ }^{\circ} \mathrm{C} \pm 1$ until its use. This residue was composed of partially crushed stones, pulp and skin and displayed an initial moisture content of $53 \mathrm{wt} \%$. Prior to dry fractionation, the fresh olive pomace was dried in an oven at $60^{\circ} \mathrm{C}$ for $24 \mathrm{~h}$ until reaching a moisture content of $9 \mathrm{wt} \%$.

A commercial grade of polyhydroxy-(butyrate-co-valerate) (PHBV) containing $5 \%$ of valerate was purchased from NaturePlast company (France) in the form of pellets (PHI002 grade). Data given by the supplier were the following: PHBV density of $1.25 \pm 0.05$, melt flow index

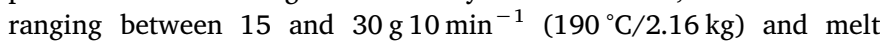
temperature ranging from 145 to $155^{\circ} \mathrm{C}$. Pellets were dried overnight at $60{ }^{\circ} \mathrm{C}$ before processing. Polypropylene (PP) in the form of pellets (PPH 9020 grade) was purchased from Total Petrochemicals (Belgium). Data given by the supplier were the following: PP density of 0.905 , melt flow

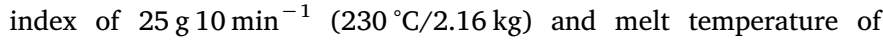
$165^{\circ} \mathrm{C}$.

Sulfuric acid, arabinose, xylose and glucose (Sigma-Aldrich), formamide, diiodomethane (Acros Organics, Geel, Belgium), ethylene glycol (Aldrich chemical Co. Inc., Milwaukee, USA) and glycerol (Merk, Darmstadt, Germany) were used for characterization of olive pomace fractions.

\subsection{Preparation of olive pomace-based fillers}

A dry fractionation process was applied to separate the pulp and the stone from the crude olive pomace (OP). Dry OP was first submitted to frictional forces in a ball mill (Marne $n^{\circ} 55$, FAURE, France) operating at ambient temperature, $86 \mathrm{rpm}$ and during $30 \mathrm{~min}$. A jar of $2 \mathrm{~L}$ was used, with $1 / 3$ in volume of ceramic balls (diameter of 15,20 and $25 \mathrm{~mm}$ ) and $1 / 3$ in volume of crude OP. The resulting powder was then passed into an electric sieve (RITEC, model 400, France) through a $1.25 \mathrm{~mm}$ mesh. Two fractions were obtained: the fine fraction was recovered at the bottom of the sieve and corresponds to the pulp-rich fraction (PF), while a coarse fraction was retained on the sieve (Lammi et al., 2018). This coarse fraction was further ground using a knife milling (SM 300, Retch, Germany) with a grid size of $1 \mathrm{~mm}$ and speed of $1500 \mathrm{rpm}$. The ground product was then sieved through a $0.4 \mathrm{~mm}$ mesh in order to separate the stone-rich fraction (SF) from the intermediate fraction (Fig. 1). Finally, in order to obtain powders with similar particle sizes, the SF and PF fractions as well as the crude OP, corresponding to the starting biomass (named $\mathrm{CF}$ ), were first reduced by knife milling using a $0.25 \mathrm{~mm}$ grid at $1500 \mathrm{rpm}$ and then further reduced using a $0.3 \mathrm{~mm}$ impact milling (Hosokawa-alpine, type 100UPZ, Augsburg, Germany) operating at $18000 \mathrm{rpm}$ (Fig. 1).

\subsection{Preparation of olive pomace-based composite films}

\subsubsection{Compounding}

To minimize hydrolytic degradation, all constituents (PHBV pellets, $\mathrm{CF}, \mathrm{SF}$ and PF powders) were dried in a vacuum oven at $60^{\circ} \mathrm{C}$ over night prior to compounding. Composites were blended at various polymer/ filler ratios $(100 / 0,95 / 5,85 / 15,70 / 30 \mathrm{w} / \mathrm{w})$ using a HAAKE Rheomix internal mixer. The polymer pellets and the OP-based fillers were first mixed manually. The resulting mixture was then introduced all at once into the mixer operating at a rotor speed of $60 \mathrm{rpm}$. The mixture was blended during $5 \mathrm{~min}$ at temperatures of $170{ }^{\circ} \mathrm{C}$ and $180{ }^{\circ} \mathrm{C}$ for PHBV and PP matrices, respectively. The obtained compounds were cooled to room temperature and then, ground in a knife mill (SM 300, Retch, Germany) at a speed of $2200 \mathrm{rpm}$ through a $4 \mathrm{~mm}$ grid to obtain composite pellets, which were then stored in sealed plastic bags containing silica gel. The codification of sample was done as follows: matrix-OP based fraction (weight filler content). For example, PHBV-CF (5\%) corresponds to a PHBV-based composite filled with $5 \mathrm{wt} \%$ of the CF fraction.

\subsubsection{Film shaping}

Compounds were dried at $60^{\circ} \mathrm{C}$ for at least $8 \mathrm{~h}$ before the preparation of films. Biocomposite films $(10.5 \mathrm{~cm}$ wide squares, average thickness about $250 \mu \mathrm{m}$ ) were prepared by hot pressing the pellets between two Teflon coated plates, at $170^{\circ} \mathrm{C}$ and $180^{\circ} \mathrm{C}$ for PHBV and PPbased biocomposites respectively, using a hydraulic thermopress (PLM $10 \mathrm{~T}$, Techmo, Nazelles, France). Samples were allowed to melt for 


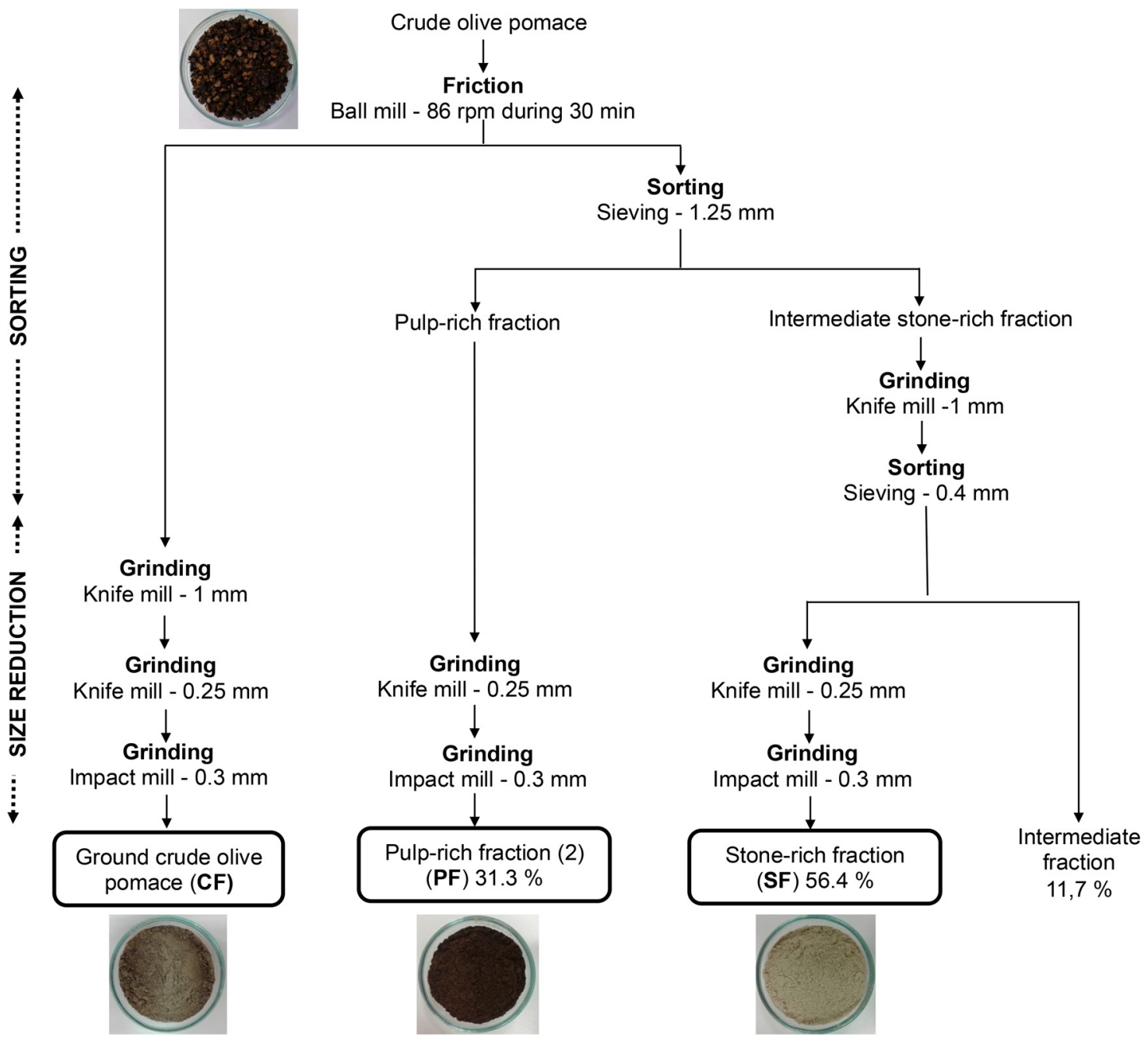

Fig. 1. Dry fractionation process of crude olive pomace.

$3 \mathrm{~min}$ then, a pressure of 150 bars was applied for $2 \mathrm{~min}$ as described by Martino et al. (2015). Finally, films were cooled at room temperature before being removed from the mold (no control of the cooling rate). Exactly the same process was applied to the neat PP and PHBV matrices.

\subsubsection{Film thickness and conditioning}

Film thickness was measured using a precision gauge (Hanatekmodel FT3, UK) on at least ten different positions for each film sample. Thickness mean values were considered in the calculation of mechanical properties, oxygen and water vapour permeability. All analyses were carried out on films samples stored in desiccators in presence of silica gel (relative humidity of 3\%). They were removed from the dessicator just before analysis according to their use.

\subsection{Characterization of olive pomace-based fillers and biocomposites}

\subsubsection{Particle size and morphology}

Particle size distributions were determined using a laser diffraction particle size analyzer (Mastersizer 2000, Malvern Instruments Ltd., United Kingdom). Powders were suspended in ethanol 95\% (v/v) directly in the experimental cell. Quantitative morphological analysis of particles was performed by image analysis using the Image $\mathrm{J}$ software. For each sample, mosaic images were assembled by reconstructing $10 \times 4$ images using the imaging software NIS-Elements (Nikon, Japon) operating with the Multizoom AZ100 system, as described by Montano-
Leyva et al. (2013). Number- and surface-weighted distributions of maximum Feret diameters, i.e. the maximum length inside the particle projection, were determined based on the analysis of roughly 300 particles. Image analysis was performed on an increasing number of particles, until the mean of the considered indicator stabilized, i.e. with a variation lower than $5 \%$, which was obtained with 80 particles in the present study. Aspect ratio of particles was calculated as the maximum Feret diameter (maximum dimension inside the particle projection) divided by the minimum Feret diameter (equivalent rectangle short side).

\subsubsection{Particle density}

The true density of OP-based powders was measured with a helium pycnometer (ULTRAPYCNOMETER 1000, Quantachrome instruments) using approximately $2 \mathrm{~g}$ of sample.

\subsubsection{Biochemical composition}

The moisture content of OP-based powders was determined by drying two grams of sample in an oven at $110^{\circ} \mathrm{C}$ until reaching weight equilibrium. The ashes content was obtained by igniting about one gram of sample in a muffle furnace at $600{ }^{\circ} \mathrm{C}$ for five hours using porcelain crucibles. Cellulose and hemicellulose contents were measured after concentrated acid hydrolysis. $10 \mathrm{mg}$ of dried samples were treated with $72 \% \mathrm{H}_{2} \mathrm{SO}_{4}$ for $1 \mathrm{~h}$ at $30^{\circ} \mathrm{C}$ followed by hydrolysis with $4 \%$ sulfuric acid for $1 \mathrm{~h}$ at $120^{\circ} \mathrm{C}$. The released monosaccharides were analyzed by a combined HPLC water system, using a BioRad HPX-87H 
column at $40{ }^{\circ} \mathrm{C}$ and $0.3 \mathrm{~mL} \mathrm{~min}^{-1}$ according the protocol described by Barakat et al. (2014). The lignin content was determined by the Klason method (Nicholson et al., 2014). The protein content $(\mathrm{N} \times 6.25)$ was determined after estimation of the nitrogen content $(\mathrm{N})$ by elementary analysis according to Jones (1941). All experiments were carried out in triplicate for each OP fraction.

\subsubsection{Surface free energy and work of adhesion}

Contact angles were measured using a goniometre (Digidrop, GBX, France) instrument, on samples fractions compressed beforehand with a hydraulic press (Perkin-Elmer) to form tablets that were stored over night with silicagel. In order to estimate the surface free energy of compressed OP-based fillers (polar $\gamma^{p}$, and dispersive $Y^{d}$ components), five reference liquids were used, i.e. distilled water, formamide, diiodomethane, ethylene glycol and glycerol. Surface free energy values were calculated by using the Owens-Wendt approach (Owens and Wendt, 1969). To calculate the work of adhesion $\left(\mathrm{W}_{\mathrm{A}}\right)$ between the matrix $m$ (PP or PHBV) and the OP-based filler $f$, the following equation derived from the Owens-Wendt approach was used:

$W_{A}=2\left[\sqrt{\gamma_{m}^{d} \gamma_{f}^{d}}+\sqrt{\gamma_{m}^{p} \gamma_{f}^{p}}\right]$

\subsubsection{Color}

The color attributes of every OP-based fractions and biocomposites were measured with a colorimeter (Minolta), using the $L^{*}, a^{*}, b^{*}$ color system. The total color difference $(\Delta \mathrm{E})$ was calculated according to CIE (2004) as following (Eq. (2)):

$\Delta E=\left[\left(L^{*}-L_{0}^{*}\right)^{2}+\left(a^{*}-a_{0}^{*}\right)^{2}+\left(b^{*}-b_{0}^{*}\right)^{2}\right]^{0.5}$

With $L^{*}, a^{*}$ and $b^{*}$ the color components of each sample. The references were respectively $\mathrm{CF}$ for SF and PF fractions, and the neat polymer matrices for biocomposites. All measurements were carried out in triplicate.

\subsubsection{Thermogravimetric analysis (TGA)}

The thermal stability of OP-based fractions and biocomposites was evaluated by TGA carried out by heating about $10 \mathrm{mg}$ of samples from room temperature up to $900^{\circ} \mathrm{C}$, at a heating rate of $10^{\circ} \mathrm{C} \mathrm{min}{ }^{-1}$ under either air or nitrogen (flow rate of $50 \mathrm{~mL} \mathrm{~min}^{-1}$ ). Three thermal degradation temperatures were recorded: $\mathrm{T}_{\text {peak }}$ which was measured from the maximum value of weight loss derivative, $\mathrm{T}_{5 \%}$ and $\mathrm{T}_{20 \%}$, which corresponds to the temperatures at which respectively $5 \mathrm{wt} \%$ and $20 \mathrm{wt}$ $\%$ of initial weight were lost.

\subsubsection{Differential scanning calorimetry (DSC)}

Differential scanning calorimetry was used to measure the crystallization $\left(\mathrm{T}_{\mathrm{c}}\right)$ and melting $\left(\mathrm{T}_{\mathrm{m}}\right)$ temperatures of materials, as well as their crystallinity $\left(\mathrm{X}_{\mathrm{c}}\right)$. Measurements were done with a thermo-modulated calorimeter (Q200 modulated DSC, TA Instruments, New Castle, USA). Around $10 \mathrm{mg}$ of film were placed in hermetic aluminum pans (Zero Aluminium Hermetic pan, TA Instruments New Castle, USA). Each sample was first heated up to $200{ }^{\circ} \mathrm{C}$ then cooled down to $-40{ }^{\circ} \mathrm{C}$ at $10^{\circ} \mathrm{C} \mathrm{min}{ }^{-1}$, and finally heated again up to $200^{\circ} \mathrm{C}$ at a heating rate of $10^{\circ} \mathrm{C} \mathrm{min}{ }^{-1}$, the first scan was used to erase the thermo-mechanical history of the samples. Crystallization temperature $\left(\mathrm{T}_{\mathrm{c}}\right)$ was measured from the exothermic peak of the cooling ramp. Melting temperatures were deduced from the endothermic peaks of the first $\left(\mathrm{T}_{\mathrm{m} 1}\right)$ and second $\left(\mathrm{T}_{\mathrm{m} 2}\right)$ heating ramp. Melting enthalpies were determined by the DSC software, from the area under the peak observed on both the first $\left(\Delta \mathrm{H}_{\mathrm{m} 1}\right)$ and the second heating $\left(\Delta \mathrm{H}_{\mathrm{m} 2}\right)$ ramp. Crystallinity of each sample was calculated with Eq. (3):

$\mathrm{Xc}=\left(\frac{\Delta \mathrm{H}_{m}}{W \times \Delta \mathrm{H}_{m}^{*}}\right) \times 100$ where $\Delta \mathrm{H}_{\mathrm{m}}$ is the apparent melting enthalpy of the sample, $W$ is polymer weight fraction in the sample and $\Delta \mathrm{H}_{\mathrm{m}}{ }^{*}$ the theoretical melting enthalpy of a $100 \%$ crystalline polymer. Values of $146 \mathrm{~J} \mathrm{~g}^{-1}$ and $148 \mathrm{~J} \mathrm{~g}^{-1}$ were respectively used for $\Delta \mathrm{H}_{\mathrm{m}}{ }^{*}$ of PHBV and PP, as reported by Barham et al. (1984) and Monasse and Haudin (1985).

\subsubsection{Tensile tests}

The mechanical properties of the different films were evaluated at room temperature through tensile tests performed with a texture analyzer (Zwick BZ2.5/TN1S, France) on dog-bone shape specimens precut with a piece cutter (width of $4 \mathrm{~mm}$ and gauge length of $45 \mathrm{~mm}$ ) and using a cross-head speed of $10 \mathrm{~mm} \mathrm{~min}^{-1}$. Nominal stress at break $\left(\sigma_{b}\right)$, nominal elongation at break $\left(\varepsilon_{\mathrm{b}}\right)$ and Young's modulus $(\mathrm{E})$ were determined from stress-strain curves. Ten replicates were realized for each formulation.

\subsubsection{Scanning electron microscopy (SEM)}

SEM observations were performed using a scanning electron microscope (SEM S-4500, Hitachi, Japan) with an acceleration voltage of $2 \mathrm{kV}$ and a detector for secondary electrons. For the observation of cryofractured surfaces, films were previously frozen under liquid nitrogen, then fractured, mounted and coated with gold/palladium on an ion sputter coater.

\subsubsection{Water vapour permeability (WVP)}

Water vapour permeability of films $\left(\mathrm{mol} \mathrm{m}^{-1} \mathrm{~s}^{-1} \mathrm{~Pa}^{-1}\right)$ was determined at $20^{\circ} \mathrm{C}$ using a gravimetric method according to the protocol described by Angellier-Coussy et al. (2011) between 0\% (permeation cells placed in a dessicator containing silicagel) and $100 \%$ of relative humidity (cells containing water). Cells were weighed using a four-digit balance (BALCO - Type LX 220A, Switzerland) every $24 \mathrm{~h}$ during one week. Five samples of each film were tested and water vapour permeability was calculated from the following equation:

$W V P=\frac{w \cdot x}{A \cdot \Delta \mathrm{p}}$

where $\mathrm{w}$ is the slope of the weight loss versus time $\left(\mathrm{mol} \mathrm{s}^{-1}\right), \mathrm{x}$ is the film thickness at equilibrium measured at the end $(\mathrm{m}), \mathrm{A}$ is the area of exposed film $\left(\mathrm{m}^{2}\right)$, and $\Delta \mathrm{p}$ is the water vapour pressure differential across the film (at $20^{\circ} \mathrm{C}, \Delta \mathrm{p}=2338 \mathrm{~Pa}$ ).

\subsubsection{Oxygen permeability}

Oxygen transmission rate (OTR) $\left(\mathrm{m}^{3} \mathrm{~m}^{-2} \mathrm{~d}^{-1}\right)$ of films was measured at $20^{\circ} \mathrm{C}$ and $0 \% \mathrm{RH}$ on $16 \mathrm{~cm}^{2}$ circular films using an oxygen permeation cell (OTR-Pst6, PresSens-GmbH, Germany) and a modified ASTM Standard (2007) procedure. The oxygen transmission rate through the material can be detected with the oxygen sensor in the upper chamber. It was determined for all specimens in duplicate and calculated according to the following formula:

$\mathrm{OTR}=\frac{\mathrm{VO} 2}{A \cdot t}$

With $\mathrm{VO}_{2}$ is oxygen volume in the upper chamber $\left(\mathrm{cm}^{3}\right), A$ is surface of the specimen area $\left(\mathrm{m}^{2}\right), t$ is the time (day).

The permeability $\left(\mathrm{PO}_{2}\right)\left(\mathrm{cm}^{3} \mathrm{~m}^{-2} \mathrm{~d}^{-1} \mathrm{~Pa}^{-1}\right)$ of the films was calculated according to equation 6 :

$\mathrm{PO} 2=\frac{O T R}{P}$

Where $P$ is the partial pressure of oxygen in the upper chamber.

The oxygen permeability coefficient $\mathrm{P}^{\prime} \mathrm{O}_{2}\left(\mathrm{~mol} \mathrm{~m}^{-1} \mathrm{~s}^{-1} \mathrm{~Pa}^{-1}\right)$ was determined as follows:

$\mathrm{P}^{\prime} \mathrm{O}_{2}=\mathrm{PO}_{2} \times l$

Where $l(\mathrm{~m})$ is the average thickness of the specimen, which was determined at five points distributed over the entire test area. 


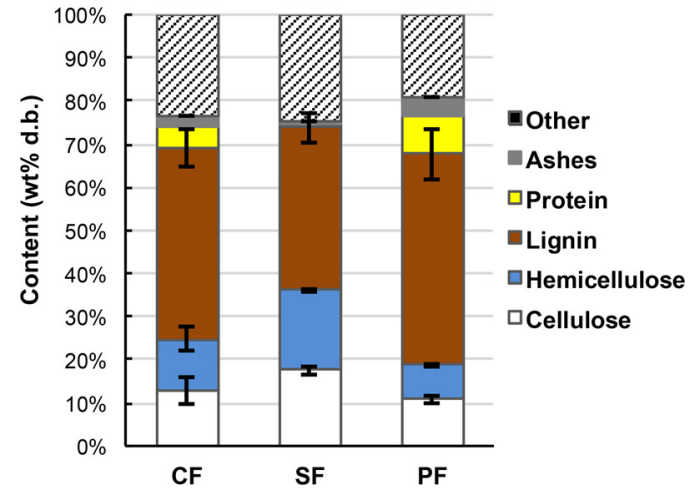

Fig. 2. Biochemical composition (dry basis) of olive pomace-based fractions, i.e. $\mathrm{CF}$ (ground crude olive pomace), SF (stone-rich fraction) and PF (pulp-rich fraction).

\section{Results and discussion}

\subsection{Effect of dry fractionation on the characteristics of olive pomace-based fillers}

\subsubsection{Effect of dry fractionation on biochemical composition, color and particle density}

On the whole, the lignocellulosic complex represented more than two thirds of the biochemical composition of OP fractions (Fig. 2). The concentration in cellulose and hemicellulose was the highest in the stone-rich fraction, with values of $36,24.8$ and $18.8 \mathrm{wt} \%$ dry basis (d.b.) for the SF, CF and PF fractions, respectively. On the opposite, lignin was more concentrated in the pulp-rich fraction, with values of 48.9, 44.3 and $37.8 \mathrm{wt} \%$ d.b. for the PF, CF and SF samples respectively. The pulp-rich fraction was also characterized by higher protein and ashes contents (protein contents of 8.7, 4.9 and $0.6 \mathrm{wt} \%$ d.b. and ashes content of 4.6, 2.6 and $0.8 \mathrm{wt} \%$ d.b. for PF, CF and SF, respectively). To summarize, the stone-rich fraction was richer in holocellulose whereas the pulp-rich fraction was richer in lignin, proteins and ashes, as compared to the crude olive pomace. These results were consistent with those already obtained from a previous study (Lammi et al., 2018) and are close to those reported by Hassaini et al. (2017) and RodríguezGutierrez et al. (2014). This confirmed that the three produced fractions displayed contrasted compositions, with an intermediate composition for the fraction CF. Such differences in biochemical compositions may be responsible for variations in intrinsic properties of powders, including their physico-chemical and mechanical properties as well as their thermal stability.

The PF sample was visually darker than the SF sample, with a dark brown and almost black color. The stone-rich fraction was characterized by a light beige color. These differences in color are related to the oxidation of fatty acids mainly in the pulp due the presence of residual oil, and also to the heterogeneous distribution of chlorophyll pigments through the different tissues of the olive. These pigments, which are responsible for the color of the fruit, are more concentrated in the pulp and the skin. The darker color of the PF fraction could also be due to a higher content in lignin and polyphenols, as compared to SF and the crude $\mathrm{CF}$ fractions. As expected, the $\mathrm{CF}$ fraction, which is a mixture of pulp and stone, displayed a light brown color intermediate between the two preceding samples. These observations were quantitatively confirmed by the measurements of the colorimetric parameters $L^{*}, a^{*}$ and $b^{*}$, with $L^{*}$ characterizing the lightness, $a^{*}$ the range of color from red to green, and $b^{*}$ the range of color from yellow to blue (Table 1). Big differences in lightness were noticed, with $L^{*}$ values of respectively 57.8, 25.2 and 36.8 for the SF, PF and CF fractions, knowing that the lower the $L$ * value, the darker the sample. Some significant differences were also recorded for $b^{*}$, with values of respectively 15.3, 7.7 and 13.5 for the SF, PF and CF fractions, that can be associated with the difference in lignin content.

Finally, as regards the true density, a significant difference was noticed between the PF fraction having a density of $1.35 \mathrm{~g} \mathrm{~cm}^{-3}$ and the $\mathrm{SF}$ and $\mathrm{CF}$ having higher densities of respectively 1.42 and $1.43 \mathrm{~g} \mathrm{~cm}^{-3}$ (Table 1). Since composite materials have been formulated by considering polymer/filler weight ratios, this means that for a given filler weight content, PF-based biocomposites will have slightly higher filler volume contents (Vf) than CF- and SF-based biocomposites (e.g. for PP-PF(15\%),Vf is $10.6 \%$ while for PP- CF(15\%) and PP-SF(15\%), Vf is roughly $10.1 \%)$.

\subsubsection{Effect of dry fractionation on particle size and morphology}

Grinding steps have been applied in such a way to obtain similar size distributions and median apparent diameters. All the fractions displayed bimodal volume-based size distributions, with a first population around $0.5 \mu \mathrm{m}$ and a second one around $40-60 \mu \mathrm{m}$ depending on the sample (Fig. 3). Median apparent diameters deduced from volumeweighted distributions $\left(d_{50}\right)$ were 84,59 and $56 \mu \mathrm{m}$ for the PF, CF and $\mathrm{SF}$ fractions, respectively (Table 1). The PF fraction had a slightly higher $d_{50}$ (about $30 \mu \mathrm{m}$ more) than the other two fractions, probably due to its composition richer in lignin, which is known to promote plant tissues cohesion and to make the biomass more recalcitrant towards the grinding processes (Barakat et al., 2013). However, this is in contradiction with other results. Indeed, Berthet et al. (2015), who compared the grindability of several lignocellulosic biomass, reported that in the case of wheat straw, the high content in cellulose and hemicellulose may hinder the obtaining of fine powders. These authors supposed that olive mills were more prone to produce fine powders due to the higher lignin content. When considering the number-weighted distributions, median diameters were respectively $0.5,0.6$ and $0.6 \mu \mathrm{m}$ for the PF, CF and SF fractions (Table 1), highlighting the presence of numerous submicronic size particles in the three samples.

SEM observations revealed that the three fractions primarily displayed a quite similar sphere-like shape with low aspect ratio (Fig. 4). This was confirmed by quantitative image analysis based on surfaceweighted distributions (Berthet et al., 2017), with aspect ratio around 1.5 for the three samples. Some elongated particles were observed on SEM pictures in the case of the stone-rich fraction, but this population of particles had no significant impact on the median aspect ratio of this sample (Table 1).

\subsubsection{Effect of dry fractionation on the thermal stability of olive pomace- based fillers}

All the fractions exhibited a similar behavior: a first weight loss occurring up to $130{ }^{\circ} \mathrm{C}$ corresponding to water loss (3.3, 4.5 and $7.2 \mathrm{wt}$ $\%$ w.b. for SF, CF and PF respectively), and one main weight loss between 150 and $350^{\circ} \mathrm{C}$ under air (or until $650^{\circ} \mathrm{C}$ under nitrogen), which corresponds to the thermal degradation of main organic compounds found in olive pomace, i.e. cellulose, hemicellulose, lignin and other non-cellulosic components (Fig. $5 \mathrm{a} 1$ and a2). Either under air or nitrogen conditions, the $\mathrm{SF}$ fraction was slightly more thermally stable than the $\mathrm{CF}$ and $\mathrm{PF}$ fractions, with a higher $\mathrm{T}_{5 \%}$ and $\mathrm{T}_{20 \%}$ values $\left(250^{\circ} \mathrm{C}\right.$ and $278{ }^{\circ} \mathrm{C}$, respectively), whereas its degradation temperature at the maximal rate $\left(\mathrm{T}_{\text {peak }}\right)$ was $282{ }^{\circ} \mathrm{C}$ against $320^{\circ} \mathrm{C}$ for $\mathrm{CF}$ and PF (Table 1 ), this is certainly explained by lignin contents in each fractions. Furthermore, considering DTG curves, the degradation peak was clearly sharper for the SF fraction richer in cellulose and hemicellulose than for $\mathrm{CF}$ and PF displaying broader peaks (Fig. $5 \mathrm{~b} 1$ and b2). In the case of $\mathrm{CF}$ and $\mathrm{PF}$, the main degradation could be deconvoluted in at least two peaks. This was ascribed to the higher content of lignin in CF and PF samples, which is known to thermally decompose over a wide temperature range from 150 to $500{ }^{\circ} \mathrm{C}$ due to the presence of various oxygen functional groups (Ozveren and Ozdogan, 2013). Under nitrogen, thermal degradation leaves 24.9, 25.7 and $26.5 \mathrm{wt} \%$ (of residue for SF, CF and PF, respectively). Under air conditions, a third weight loss was observed from 360 to $510{ }^{\circ} \mathrm{C}$, corresponding to the oxidation 
Table 1

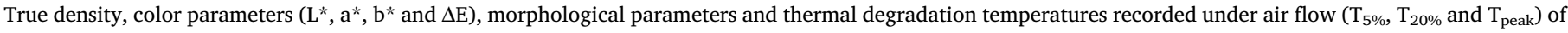
olive pomace-based fillers.

\begin{tabular}{|c|c|c|c|c|c|c|c|c|c|c|c|}
\hline & $\begin{array}{l}\text { True density } \\
\left(\mathrm{g} \mathrm{cm}^{-3}\right)\end{array}$ & $L^{*}$ & $a^{*}$ & $b^{*}$ & $\Delta E$ & $\begin{array}{l}\text { Median } d_{50} \text { in } \\
\text { volume }(\mu \mathrm{m})^{\mathrm{a}}\end{array}$ & $\begin{array}{l}\text { Median } d_{50} \text { in } \\
\text { number }(\mu \mathrm{m})\end{array}$ & $\begin{array}{l}\text { Median aspect } \\
\text { ratio in surface }\end{array}$ & $\mathrm{T}_{5 \%}\left({ }^{\circ} \mathrm{C}\right)$ & $\mathrm{T}_{20 \%}\left({ }^{\circ} \mathrm{C}\right)$ & $\mathrm{T}_{\text {peak }}\left({ }^{\circ} \mathrm{C}\right)$ \\
\hline $\mathrm{CF}$ & $1.43 \pm 0.01$ & $36.8 \pm 0.2$ & $8.2 \pm 0.0$ & $13.5 \pm 0.0$ & - & $59 \pm 2(4.4)$ & $0.55 \pm 0.02$ & $1.47(0.71)$ & $227 \pm 4$ & $272 \pm 1$ & $320 \pm 0$ \\
\hline SF & $1.42 \pm 0.00$ & $57.8 \pm 0.2$ & $6.6 \pm 0.1$ & $15.3 \pm 0.0$ & $21.2 \pm 0.2$ & $56 \pm 2(3.6)$ & $0.59 \pm 0.01$ & $1.42(0.52)$ & $250 \pm 0$ & $278 \pm 1$ & $282 \pm 3$ \\
\hline $\mathrm{PF}$ & $1.35 \pm 0.00$ & $25.2 \pm 0.3$ & $7.4 \pm 0.1$ & $7.7 \pm 0.3$ & $13.0 \pm 0.4$ & $84 \pm 7(4.2)$ & $0.53 \pm 0.02$ & $1.47(0.43)$ & $212 \pm 2$ & $264 \pm 0$ & $321 \pm 1$ \\
\hline
\end{tabular}

a Value in parenthesis corresponded to the span value $\left(\operatorname{span}=\left(d_{90}-d_{10}\right) / d_{50}\right)$.

b Calculated from image analysis results.

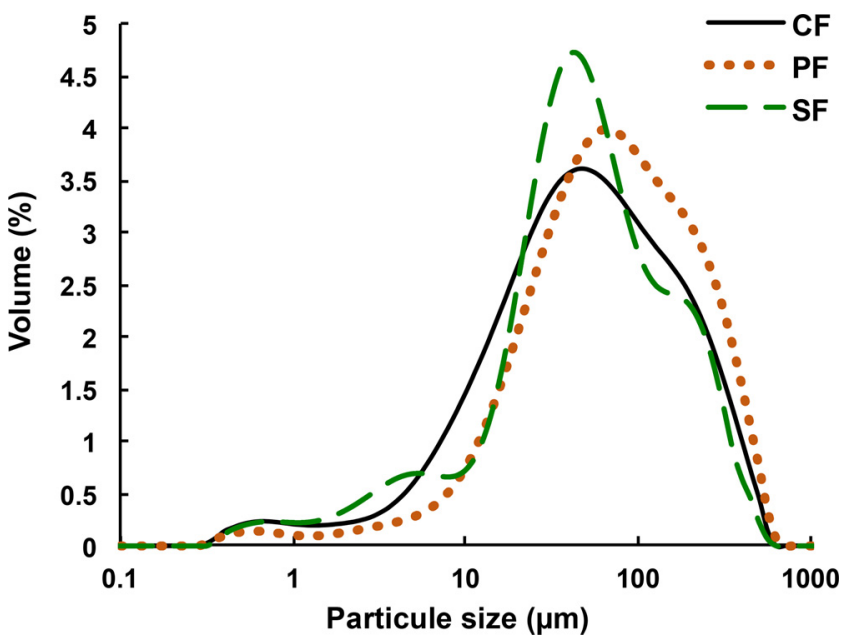

Fig. 3. Particle size distribution of olive pomace fractions.

reactions of aromatic rings of lignin and of the residue formed during the first degradation step (Shafizadeh et al., 1972; Tejado et al., 2007; Yang et al., 2007). The residual matter corresponds to ashes and was 3.3, 3.5 and $6.5 \mathrm{wt} \%$ w.b for SF, CF and PF, respectively.

Based on these results, it should be pointed out that thermal degradation of all OP-based fractions occurs at temperatures much higher than the melting point $\left(\mathrm{T}_{\mathrm{m}}\right)$ of many conventional thermoplastic polymers, including PP and PHBV. As an example, a weight loss of $5 \mathrm{wt} \%$ w.b. was recorded at 212,227 and $250^{\circ} \mathrm{C}$ for the $\mathrm{PF}, \mathrm{CF}$ and $\mathrm{SF}$ fractions, respectively. This makes OP-based fractions sufficiently thermally stable to be used as fillers in thermoplastic biocomposites.

\subsubsection{Effect of dry fractionation on the surface energy of olive-pomace based fillers}

On the basis of contact angle $\theta\left({ }^{\circ}\right)$ measurements and calculated surface free energy $\gamma\left(\mathrm{mJ} . \mathrm{m}^{-2}\right)$, it appears that the three produced fractions displayed different wettability properties (Table 2). SF appeared as the most polar fraction, with the lowest contact angle with water $\left(\theta=59^{\circ}\right)$, the highest polar component $\left(\gamma^{p}=9.7 \mathrm{~mJ} \mathrm{~m}^{-2}\right)$ and the lowest dispersive component $\left(\gamma^{d}=28.9 \mathrm{~mJ} \mathrm{~m}^{-2}\right)$ of the surface free energy. These results were explained by the higher content of hydrophilic compounds, i.e. cellulose and hemicelluloses, in the stone-rich fraction. On the other hand, the PF fraction was the most apolar. This latter displayed the highest contact angle value with water $\left(\theta=75^{\circ}\right)$, the lowest polar component $\left(\gamma^{p}=2.7 \mathrm{~mJ} \mathrm{~m}^{-2}\right)$ and the highest dispersive component $\left(\gamma^{d}=37.6 \mathrm{~m} \mathrm{Jm}^{-2}\right)$ of the surface free energy. This was explained by the richer composition in lignin of PF fraction as compared to the two other fractions, which is known to bring water impermeability to plants and reduce the polar character of the filler surface (Le Digabel et al., 2004). The higher hydrophobicity of the pulprich fraction could also be attributed to the presence of residual oil in this tissue. As reported by Rigane et al. (2012), the fat content of olive pomace is less than $2 \%$ and Maymone et al. (1961), confirmed that the pulp is rich in oil, i.e. more than $50 \%$. Regarding the starting fraction $\mathrm{CF}$, it displayed intermediate wettability properties between those of the pulp and stone-rich fractions. These results highlighted the efficiency of the applied dry fractionation process to separate the pulp from the stone and produce olive pomace-based fractions with contrasted surface properties.

The predicted work of adhesion between the matrix and the filler was calculated for each formulation based on surface free energy of each constituent, i.e. fillers and matrices (Table 2). Work of adhesion values are similar to those reported in literature for other ligno-cellulosic substrates with thermoplastic matrices (Fuentes et al., 2015; Tran et al., 2013). Little differences could be noticed between the three fractions towards PP and PHBV. The pulp-rich fraction is expected to exhibit the highest affinity towards both matrices due to its lower polar character and highest surface free energy (work of adhesion of $72 \mathrm{~mJ} \mathrm{~m}^{-2}$ for the two matrices) while the stone-rich fraction is expected to be slightly less compatible with the matrices due to its higher polar character and lower surface free energy (work of adhesion of 69 and $66 \mathrm{~mJ} \mathrm{~m}^{-2}$ with PP and PHBV, respectively).

\subsection{Structure of olive pomace-based biocomposites}

\subsubsection{Visual appearance of films}

PF-based composites appeared homogeneous for all tested filler contents, whereas SF- and CF -based composites exhibited a
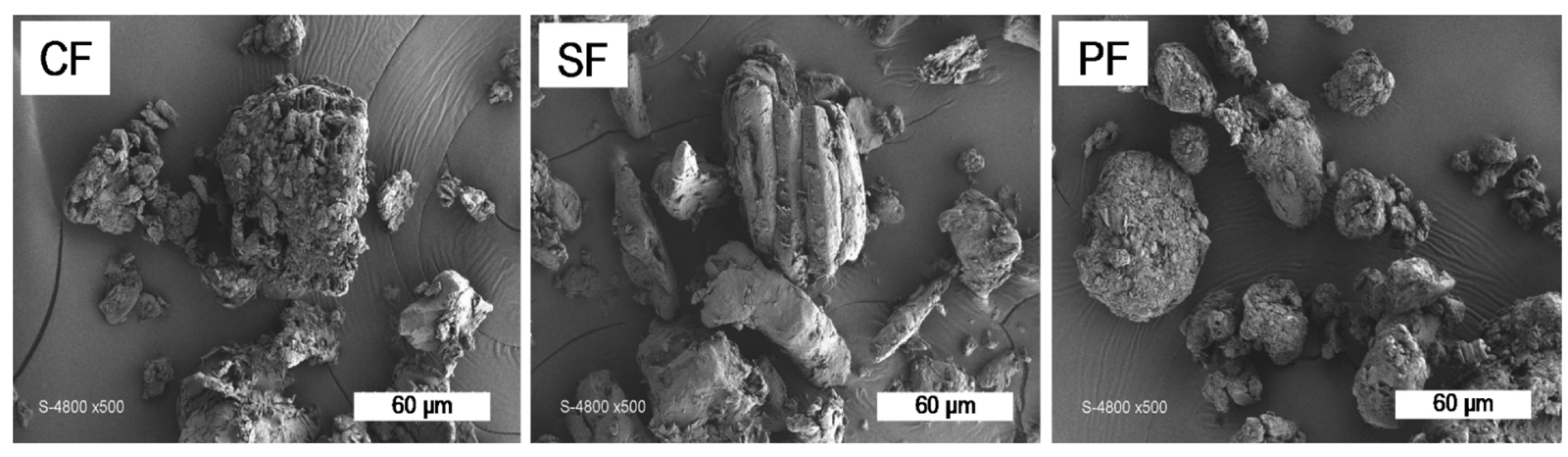

Fig. 4. SEM images of CF, SF and PF fillers (scale bar $=60 \mu \mathrm{m}$ ). 
(a1 - air)

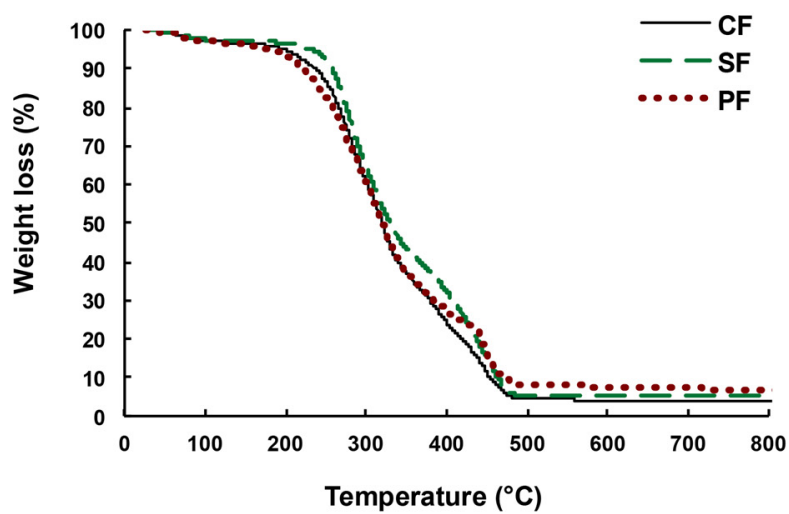

(b1 - air)

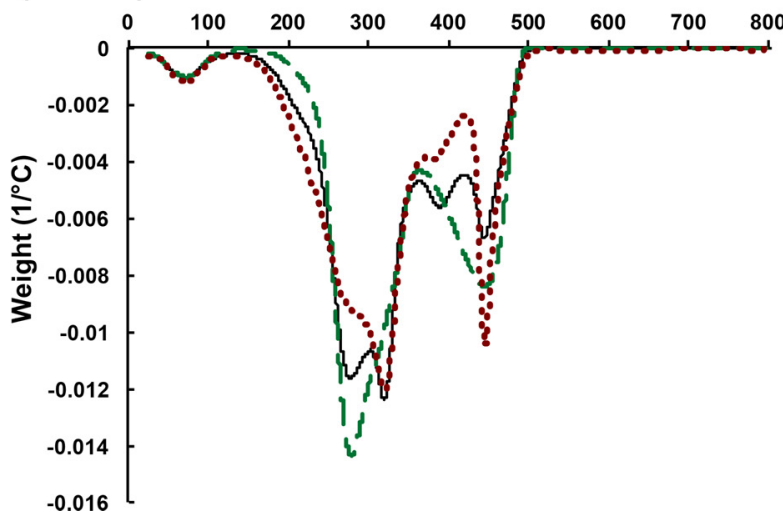

$\left(\mathrm{a} 2-\mathbf{N}_{2}\right)$

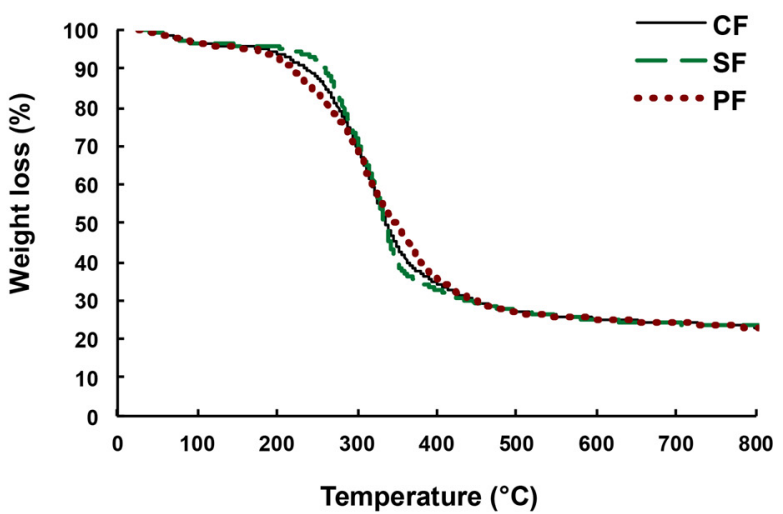

$\left(b 2-\mathbf{N}_{2}\right)$

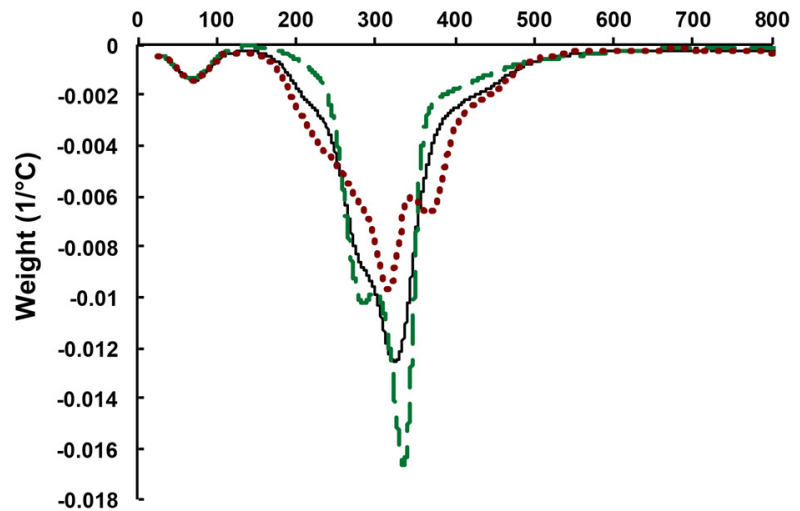

Fig. 5. TGA (a) and DTG (b) curves of CF, SF and PF fractions under air (a1 and b1) and nitrogen (a2 and b2).

macroscopic heterogeneity for filler contents higher than $15 \mathrm{wt} \%$. This heterogeneity was characterized by irregularities at the surfaces of films, resulting in a rough surface and was accentuated at a filler ratio of $30 \mathrm{wt} \%$. This was particularly pronounced in the case of SF-based materials, which became more friable with the presence of micro-cracks and holes due to visible filler particles agglomerations. Such differences in the appearance of films could be explained by the respective affinity of fillers towards matrices, in particular by their respective polarity and surface free energy (Fig. 2 and Table 2). It is assumed that the ligninrich PF fraction being more hydrophobic should show a better affinity towards PP and PHBV, thus leading to a better dispersion of the fillers within both matrices.

Colorimetric parameters are very important in the field of food packaging as regards consumer acceptability. Transparency or even translucence is often requested by consumers in order to be able to see the product. However, it is worth noting that in the case of rigid and opaque composite materials dedicated to trays applications, the use of a transparent lid film would allow to fulfill this requirement. Finally, the opacity could be required for some food products such as fatty foods in order to hinder oxidative degradation reactions by acting as a barrier to light (Romani et al., 2017). Concerning the produced biocomposite films, PF-based formulations were visually dark brown and opaque while SF-based composites were also opaque and had a light beige color. CF-based materials displayed an intermediate light brown color. These observations were confirmed by colorimetric analyzes carried out on PP and PHBV biocomposites filled with $15 \mathrm{wt} \%$ of olive pomacebased fractions (Table 3 ). The difference of color $(\Delta \mathrm{E})$ between biocomposites and the respective virgin polymer matrix was 63.1 and 56.7 for the PP-PF and PHBV-PF formulations, against 31.8 and 25.7 for the PP-SF and PHBV-SF formulations. The lightness values $\left(L^{*}\right)$ recorded for the PP-PF and PHBV-PF were 35.8 and 34.7, respectively, indicating that the difference in lightness between the two matrices was erased in presence of the PF fraction. Furthermore, whatever the formulation, increasing filler content led to an increase in the darkness of the films. The resulting color of biocomposites was clearly dependent on the color of the fillers, which is an intrinsic property related to their biochemical composition.

\subsubsection{Observation of the microstructure}

SEM observations on cryo-fractured films were done to qualitatively

Table 2

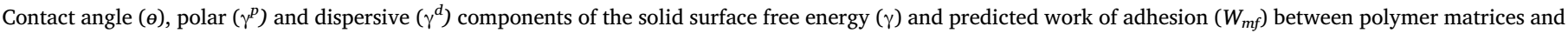
OP-based fillers.

\begin{tabular}{|c|c|c|c|c|c|c|c|c|c|c|}
\hline & \multicolumn{5}{|c|}{ Contact angle $\theta\left(^{\circ}\right)$} & \multicolumn{3}{|c|}{ Surface free energy $\left(\mathrm{mJ} \mathrm{m}^{-2}\right)$} & \multicolumn{2}{|c|}{ Predicted work of adhesion $\left(\mathrm{W}_{\mathrm{A}}\right)\left(\mathrm{mJ} \mathrm{m}^{-2}\right)$} \\
\hline & Water & Ethylene glycol & Diiodomethane & Formamide & Glycerol & $\gamma$ & $\gamma^{\mathrm{p}}$ & $\gamma^{\mathrm{d}}$ & $\mathrm{W}_{\text {PP-filler }}$ & $\mathrm{W}_{\text {PHBV-filler }}$ \\
\hline $\mathrm{CF}$ & $66 \pm 1$ & $56 \pm 2$ & $30 \pm 5$ & $53 \pm 7$ & $83 \pm 3$ & 38.5 & 6.3 & 31.8 & 69 & 68 \\
\hline SF & $59 \pm 1$ & $58 \pm 4$ & $35 \pm 4$ & $46 \pm 3$ & $82 \pm 3$ & 38.5 & 9.7 & 28.9 & 69 & 66 \\
\hline $\mathrm{PF}$ & $75 \pm 2$ & $56 \pm 2$ & $26 \pm 3$ & $45 \pm 3$ & $87 \pm 3$ & 40.2 & 2.7 & 37.6 & 72 & 72 \\
\hline PP & $80 \pm 6$ & $71 \pm 6$ & $40 \pm 7$ & $67 \pm 3$ & $85 \pm 5$ & 32.1 & 2.8 & 29.3 & - & - \\
\hline PHBV & $90 \pm 6$ & $75 \pm 4$ & $45 \pm 4$ & $69 \pm 5$ & $83 \pm 8$ & 32.2 & 1 & 31.2 & - & - \\
\hline
\end{tabular}


Table 3

Colorimetric attributes $\left(L^{*}, a^{*}, b^{*}\right.$ and $\left.\Delta \mathrm{E}\right)$ of biocomposites filled with $15 \mathrm{wt} \%$ of OP-based fillers.

\begin{tabular}{|c|c|c|c|c|}
\hline & $L^{*}$ & $a^{*}$ & $b^{*}$ & $\Delta \mathrm{E}$ \\
\hline PHBV (control) & $88.5 \pm 0.3$ & $-0.5 \pm 0.0$ & $20.6 \pm 0.4$ & - \\
\hline PHBV-CF(15\%) & $41.5 \pm 0.1$ & $8.7 \pm 0.1$ & $10.3 \pm 0.1$ & $49.0 \pm 0.1$ \\
\hline PHBV-SF(15\%) & $65.1 \pm 0.2$ & $4.6 \pm 0.0$ & $26.4 \pm 0.0$ & $25.7 \pm 0.2$ \\
\hline PHBV-PF(15\%) & $34.7 \pm 0.5$ & $8.6 \pm 0.2$ & $3.2 \pm 0.0$ & $56.7 \pm 0.5$ \\
\hline PP (control) & $97.8 \pm 0.0$ & $-0.8 \pm 0.0$ & $4.4 \pm 0.0$ & - \\
\hline PP-CF(15\%) & $48.4 \pm 0.1$ & $11.7 \pm 0.1$ & $22.8 \pm 0.1$ & $54.1 \pm 0.0$ \\
\hline PP-SF(15\%) & $74.6 \pm 0.1$ & $4.7 \pm 0.4$ & $25.6 \pm 0.4$ & $31.8 \pm 0.2$ \\
\hline PP-PF(15\%) & $35.8 \pm 0.2$ & $10.7 \pm 0.0$ & $8.4 \pm 0.1$ & $63.1 \pm 0.1$ \\
\hline
\end{tabular}

investigate the microstructure of biocomposites. Fig. 6 presents images obtained for PP-based biocomposites. The cross-section of neat PP films was quite smooth and uniform. The incorporation of either $\mathrm{CF}$ or SF fillers led to a very heterogeneous and rough section with the presence of many holes, due to debonding of particles. This evidences the very poor interfacial adhesion between the PP polymer matrix and CF or SF particles. This certainly justifies the different chemical treatments of olive stone powders applied by several authors in order to improve their compatibility with polymer matrices (Djidjelli et al., 2007; Gharbi et al., 2014; Hammoui et al., 2015; Hassaini et al., 2017). In contrast, the cryo-fractured section of PF-based biocomposites appeared very homogeneous with particles well embedded by the polymer, highlighting a good interfacial adhesion between the two constituents. It is worth noting that similar observations were found for PHBV-based biocomposites. Furthermore, these results are in agreement with the predicted values of work of adhesion. Based on these observations, variations in functional properties between the different PP- and PHBVbased biocomposites are expected.

\subsubsection{Melting and crystallization behavior}

DSC analysis was carried out on biocomposites filled with $15 \mathrm{w} \%$ of OP-based particles (Table 4). The effect of processing was analyzed based on the comparison of the first and second heating thermograms. PP-based materials were thermally very stable, with identical values of melting temperatures for either the first or the second heating ramp. In the case of PHBV-based materials, $\mathrm{T}_{\mathrm{m} 1}$ were significantly higher than $\mathrm{T}_{\mathrm{m} 2}$ values (from 4 to $7^{\circ} \mathrm{C}$ ) for all the formulations, meaning that PHBV crystals with higher thermal stability (corresponding to higher melting temperature) were formed during processing. This could be related to the slow cooling rate applied during the manufacturing of the
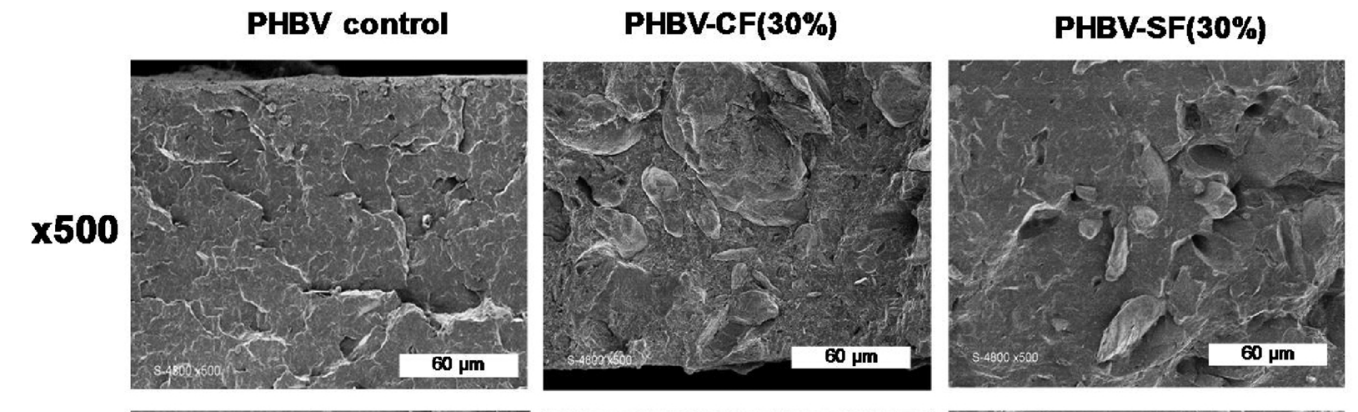

\section{PHBV-PF(30\%)}
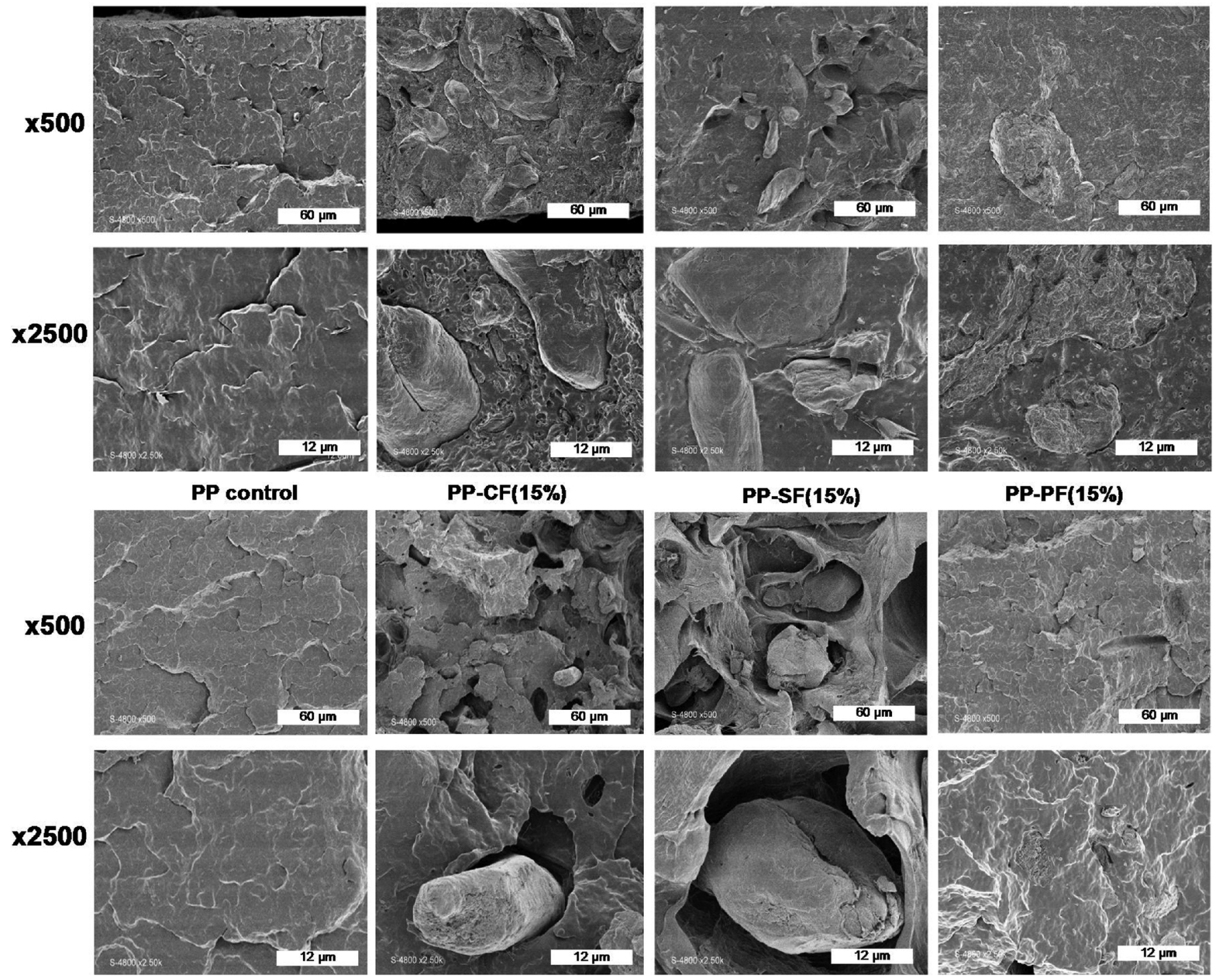

Fig. 6. SEM images of cryo-fractured surfaces of PP and PHBV-based composites filled with respectively $15 \mathrm{wt} \%$ and $30 \mathrm{wt} \%$ of either CF, SF and PF fillers (x 500 : scale bar $=60 \mu \mathrm{m}$; $\mathrm{x} 2500$ : scale bar $=12 \mu \mathrm{m})$. 
Table 4

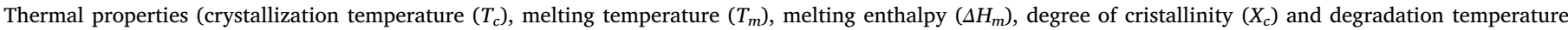
$\left(T_{\text {onset }}, T_{\text {peak }}, T_{\text {offset }}\right)$ ) of biocomposites filled with $15 \mathrm{wt} \%$ of OP-based fillers.

\begin{tabular}{|c|c|c|c|c|c|c|c|c|c|c|}
\hline & $\mathrm{T}_{\mathrm{C}}\left({ }^{\circ} \mathrm{C}\right)$ & $\mathrm{T}_{\mathrm{m} 1}\left({ }^{\circ} \mathrm{C}\right)$ & $\Delta \mathrm{H}_{\mathrm{m} 1}\left(\mathrm{Jg}^{-1}\right)$ & $\mathrm{X}_{\mathrm{c} 1}(\%)$ & $\mathrm{T}_{\mathrm{m} 2}\left({ }^{\circ} \mathrm{C}\right)$ & $\Delta \mathrm{H}_{\mathrm{m} 2}\left(\mathrm{~J} \mathrm{~g}^{-1}\right)$ & $\mathrm{X}_{\mathrm{c} 2}(\%)$ & $\mathrm{T}_{\text {onset }}\left({ }^{\circ} \mathrm{C}\right)$ & $\mathrm{T}_{\text {peak }}\left({ }^{\circ} \mathrm{C}\right)$ & $\mathrm{T}_{\text {offset }}\left({ }^{\circ} \mathrm{C}\right)$ \\
\hline PHBV (control) & $121 \pm 0$ & $175 \pm 2$ & $85 \pm 2$ & $59 \pm 2$ & $171 \pm 1$ & $93 \pm 2$ & $75 \pm 1$ & $249 \pm 3$ & $293 \pm 0$ & $312 \pm 1$ \\
\hline PHBV-CF(15\%) & $114 \pm 1$ & $169 \pm 1$ & $77 \pm 1$ & $46 \pm 4$ & $162 \pm 1$ & $80 \pm 3$ & $65 \pm 2$ & $199 \pm 2$ & $260 \pm 1$ & $531 \pm 1$ \\
\hline PHBV-SF(15\%) & $118 \pm 0$ & $171 \pm 1$ & $79 \pm 2$ & $43 \pm 0$ & $167 \pm 0$ & $85 \pm 2$ & $68 \pm 1$ & $208 \pm 0$ & $272 \pm 0$ & $517 \pm 1$ \\
\hline PHBV-PF(15\%) & $122 \pm 3$ & $168 \pm 1$ & $81 \pm 1$ & $53 \pm 3$ & $164 \pm 1$ & $96 \pm 6$ & $78 \pm 1$ & $196 \pm 1$ & $254 \pm 1$ & $514 \pm 4$ \\
\hline PP (control) & $132 \pm 0$ & $165 \pm 1$ & $94 \pm 1$ & $63 \pm 1$ & $164 \pm 0$ & $110 \pm 1$ & $74 \pm 1$ & $220 \pm 0$ & $402 \pm 2$ & $425 \pm 2$ \\
\hline PP- CF $(15 \%)$ & $127 \pm 1$ & $165 \pm 0$ & $86 \pm 5$ & $68 \pm 5$ & $164 \pm 1$ & $92 \pm 4$ & $73 \pm 3$ & $201 \pm 1$ & $390 \pm 1$ & $494 \pm 1$ \\
\hline PP-SF(15\%) & $127 \pm 0$ & $166 \pm 1$ & $82 \pm 1$ & $65 \pm 1$ & $165 \pm 0$ & $94 \pm 2$ & $75 \pm 2$ & $213 \pm 2$ & $389 \pm 1$ & $504 \pm 5$ \\
\hline PP-PF(15\%) & $122 \pm 6$ & $166 \pm 1$ & $80 \pm 2$ & $63 \pm 1$ & $164 \pm 0$ & $91 \pm 1$ & $72 \pm 0$ & $194 \pm 4$ & $400 \pm 4$ & $490 \pm 3$ \\
\hline
\end{tabular}

biocomposite films by thermocompression that could induce changes in the crystallization process of PHBV, possibly the formation of more perfect crystals.

Besides, the melting temperature $\mathrm{T}_{\mathrm{m}}$ of PHBV was significantly decreased after the incorporation of OP-based fillers. As an example, $\mathrm{T}_{\mathrm{m} 2}$ decreased from $171{ }^{\circ} \mathrm{C}$ to 167,164 and 162 for films filled with $15 \mathrm{wt} \%$ of SF, PF and CF, respectively. As already demonstrated by Berthet et al. (2015), this decrease in melting temperature in the presence of lignocellulosic fillers is most probably related to a decrease in PHBV molecular weight owing to both thermal and hydrolytic degradation reactions of chains during the thermo-mechanical processing of materials. As regards the crystallization temperature $\mathrm{T}_{\mathrm{c}}$, it decreased from $121^{\circ} \mathrm{C}$ for the neat PHBV matrix to $118^{\circ} \mathrm{C}$ and $114^{\circ} \mathrm{C}$ for PHBV-SF and PHBV- CF composites respectively, while it was not impacted by the presence of PF fillers. This suggests that the presence of CF and SF fillers could hinder the crystallization process by delaying the nucleation. Additional analyses by polarized light microscopy and isothermal DSC should be performed to investigate the effect of OP-based fillers on the crystallization kinetics of PHBV matrix. Finally, the degree of crystallinity Xc of PHBV-based materials was significantly decreased in the presence of SF and CF fillers until $68 \%$ and $65 \%$ respectively, while it was increased in the case of PF fillers from 75\% up to 78\% (Table 4). This phenomenon is not process-dependent since it is observed for both first and second heating. It suggests that PF particles favored the crystallization of PHBV, in relation with the higher ashes content in PF and/ or to enhanced interactions with the matrix, as already reported by Calabia et al. (2013). In the case of PP-based biocomposites, thermal properties and degree of crystallinity of the polymer matrix were not significantly impacted by the introduction of olive pomace-based fillers (Table 4).

\subsection{Functional properties of olive-pomace based biocomposites films}

\subsubsection{Thermal stability}

Thermal stability of biocomposites is an important property for packaging likely to be heated during their service use. It was investigated by thermogravimetric analysis under oxidative atmosphere (Fig. 7). Both polymer matrices displayed one main degradation peak, with a clearly sharper drop in the case of neat PHBV. Biocomposites showed a thermal behavior similar to their main constituents, i.e. the polymer matrix and lignocellulosic fillers. Globally, the introduction of olive pomace-based fillers resulted in a reduction of the thermal stability, with a thermal degradation beginning at low temperatures and occurring in a wider temperature range as compared to the neat matrix (Table 4). This was due to the previously reported lower thermal stability of lignocellulosic fillers as compared to the polymer matrices (Table 1). As expected, the more thermally stable the filler, the more thermally stable the biocomposites, as illustrated by the higher thermal stability of SF-based biocomposites. In the case of PP-based composites, the decrease in thermal stability follows a rule of mixture according to the respective contents of PP and fillers (see Fig. 7a for PP-CF(15\%)). This evidences the high thermal stability of PP and the fact that the
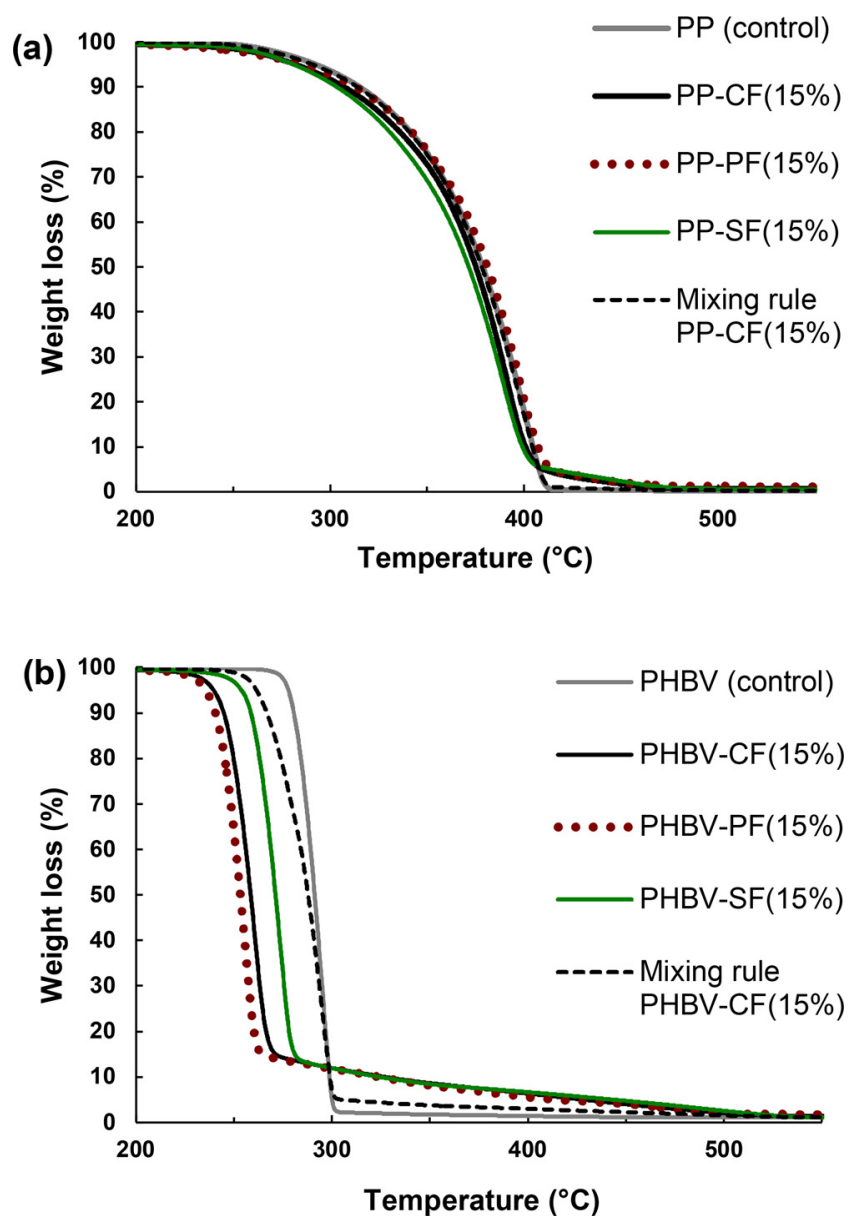

Fig. 7. TGA curves of (a) PP and (b) PHBV-based biocomposites under air.

thermal stability of the composites was not influenced by negative filler/polymer interactions. In the case of PHBV-based materials, the reduction of the thermal stability was more pronounced and did not follow a simple rule of mixture (see Fig. $7 \mathrm{~b}$ for PHBV-CF(15\%)). PHBV is known to be very sensitive towards temperature, especially above its melting point, due to the concomitance of two thermal degradation mechanisms of PHBV, i.e. a random chain scission by cis-elimination and trans-esterification reactions in a lesser extent (Leroy et al., 2012). As already well described by Berthet et al. (2015) and later by Hassaini et al. (2017), the introduction of lignocellulosic fillers induces additional hydrolytic degradation reactions through chain scission reactions at ester linkages due to the inherent presence of residual water molecules (even if dried before processing) and degradation products (alcohols and carboxylates) on lignocellulosic particles. It was demonstrated that the introduction of lignocellulosic fillers negatively impacts the thermal stability of PHBV (Berthet et al., 2015). Hopefully, the 
Table 5

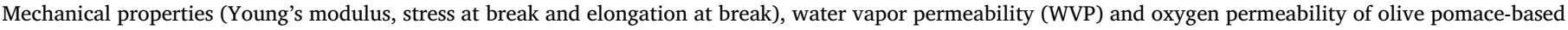
biocomposites (n.d.: not determined).

\begin{tabular}{|c|c|c|c|c|c|}
\hline Samples & Elongation at break (\%) & Stress at break (MPa) & Young's modulus (GPa) & $\mathrm{WVP} \times 10^{12}\left(\mathrm{~mol} \mathrm{~m}^{-1} \mathrm{~s}^{-1} \mathrm{~Pa}^{-1}\right)$ & $\mathrm{PO}_{2} \times 10^{17}\left(\mathrm{~mol} \mathrm{~m}^{-1} \mathrm{~s}^{-1} \mathrm{~Pa}^{-1}\right)$ \\
\hline PHBV control & $2.3 \pm 0.3$ & $34.2 \pm 4.0$ & $2.7 \pm 0.4$ & $0.9 \pm 0.1$ & $78.9 \pm 5.6$ \\
\hline PHBV- CF(5\%) & $1.7 \pm 0.2$ & $27.8 \pm 3.5$ & $2.9 \pm 0.2$ & $1.1 \pm 0.2$ & n.d. \\
\hline PHBV- CF(15\%) & $1.2 \pm 0.2$ & $18.1 \pm 3.0$ & $2.4 \pm 0.2$ & $1.5 \pm 0.0$ & $80.1 \pm 3.9$ \\
\hline PHBV- CF(30\%) & $1.0 \pm 0.2$ & $11.9 \pm 2.0$ & $2.2 \pm 0.2$ & $15.1 \pm 2.6$ & n.d. \\
\hline PHBV-SF(5\%) & $1.4 \pm 0.2$ & $26.5 \pm 3.6$ & $2.7 \pm 0.2$ & $0.3 \pm 0.0$ & n.d. \\
\hline PHBV-SF(15\%) & $1.2 \pm 0.2$ & $18.5 \pm 4.8$ & $2.5 \pm 0.4$ & $1.8 \pm 0.2$ & $85.9 \pm 10.6$ \\
\hline PHBV-SF(30\%) & $0.6 \pm 0.1$ & $7.7 \pm 3.0$ & $2.2 \pm 0.5$ & $3.9 \pm 0.2$ & n.d. \\
\hline PHBV-PF(5\%) & $2.1 \pm 0.1$ & $26.7 \pm 2.1$ & $2.4 \pm 0.2$ & $0.5 \pm 0.1$ & n.d. \\
\hline PHBV-PF(15\%) & $1.5 \pm 0.3$ & $17.9 \pm 2.6$ & $2.2 \pm 0.2$ & $0.7 \pm 0.2$ & $87.2 \pm 2.6$ \\
\hline PHBV-PF(30\%) & $1.5 \pm 0.1$ & $21.7 \pm 1.3$ & $2.4 \pm 0.1$ & $1.0 \pm 0.2$ & n.d. \\
\hline PP control & $8.5 \pm 1.1$ & $28.8 \pm 3.6$ & $1.3 \pm 0.1$ & $0.6 \pm 0.1$ & $63.9 \pm 2.7$ \\
\hline PP- CF(15\%) & $3.7 \pm 0.5$ & $18.9 \pm 1.1$ & $1.3 \pm 0.1$ & $1.1 \pm 0.1$ & $63.6 \pm 3.9$ \\
\hline PP-SF(15\%) & $3.3 \pm 0.3$ & $17.5 \pm 2.4$ & $1.4 \pm 0.2$ & $1.2 \pm 0.3$ & $64.8 \pm 2.4$ \\
\hline PP-PF(15\%) & $5.2 \pm 0.6$ & $19.1 \pm 1.2$ & $1.2 \pm 0.1$ & $0.7 \pm 0.1$ & $67.0 \pm 2.4$ \\
\hline
\end{tabular}

degradation temperatures remained relatively high for all the formulations, i.e. above $200{ }^{\circ} \mathrm{C}$, if considering the heating up temperatures typically used for food products protected by packages.

\subsubsection{Mechanical properties}

Mechanical properties of materials were investigated through tensile tests. Due to their low aspect ratio, the introduction of olive pomace-based fillers did not significantly impact the Young's modulus of either PP or PHBV within the range of tested filler contents (Table 5). However, a strong effect was noticed regarding ultimate properties. Whatever the filler or the matrix, a reduction of the material stress and strain at break was noticed. This decrease was all the more important with increasing filler amounts and depending on OP-based filler type. At low filler contents (below $15 \mathrm{wt} \%$ ), no effect of filler type was observed. While for high filler content (30 wt $\%$ ), the decrease in stress at break was more pronounced for SF and $\mathrm{CF}$ fractions. As an example, a stress at break reduction of $36 \%$ was recorded for the PHBV-PF (30\%), while it was more than the double (78\%) for the PHBV-SF (30\%) material. A similar effect was noticed for the elongation at break. In general, the highest reduction rates were recorded with SF-based composites, which were for example $39 \%, 61 \%$ and $74 \%$ for PHBV-SF materials filled with respectively 5,15 and $30 \mathrm{wt} \%$ of SF. On the other hand, the elongation at break of PF-based formulations was better preserved, with reductions of $9 \%$ and $35 \%$ for filler contents of respectively 5 and $30 \mathrm{wt} \%$. It is worth noting that ultimate properties were better preserved in the case of PP-based materials. As an example, a reduction of the tress of break of respectively $34-39 \%$ and $47 \%$ for PP and PHBV filled with $15 \mathrm{wt} \%$ of fillers (whatever the composition). Similar results were reported for olive pomace/polypropylene-based biocomposites (Ayrilmis and Buyuksari, 2010; Siracusa et al., 2001).

In general, the functional properties of composite materials are governed by (i) intrinsic properties of each constituent, including their chemical composition and structure, (ii) the filler aspect ratio, dispersion state and content, and (iii) the quality and quantity of interactions at the filler/matrix interface (Berthet et al., 2015, 2017). For all the formulations considered in the present study, the loss in the ultimate tensile performances could be directly related to the quality of the filler/matrix interfacial adhesion. It should also be pointed out that the low aspect ratios (Table 1) of OP-based fillers do not favor the development of large interfacial areas.

In the case of poor filler/matrix interactions, as revealed for SF- and CF-based composites by SEM observations, mechanical failure will occur at the interface and be favored by the presence of gaps between the matrix and the fillers. Furthermore, increasing filler content would favor the agglomeration of lignocellulosic particles, leading to the creation of microscopic and macroscopic defects, including voids, within the material, hence constituting a fragile zone conducive to the initiation and propagation of macro-cracks. This agglomeration phenomenon should be more pronounced for the fractions having a poor affinity towards the polymer matrix. Finally, in the case of PHBV-based materials, changes in tensile properties could also be related to matrix structural changes induced by the presence of fillers, including the degradation of the polymer molecular weight and decrease in degree of crystallinity, that favor a loss of both stress and strain at break. In the case of PHBV/PF composites, the higher degree of crystallinity (calculated from the first heating ramp, Table 4) as well as better interfacial adhesion (slightly higher work of adhesion) could explain the better preservation of ultimate properties compared to SF- and CF-based composites. The fact that mechanical properties of PP-based materials were better preserved than those based on PHBV could be explained by a slightly higher affinity of fillers towards PP, as suggested by the predicted work of adhesion, and also to the fact that macromolecular and crystalline structure of PP was not significantly affected by the presence of olive pomace-based fillers, in particular no degradation occurred upon processing by extrusion and thermocompression.

It is possible to describe the composition dependence of the tensile strength of polymer composites using interfacial adhesion models as proposed by Pukánszky (1990):

$\left(\sigma_{c}=\sigma_{m} \lambda^{n}\left(\frac{1-x_{f}}{1+2.5 x_{f}}\right) e^{\left(B x_{f}\right)}\right.$

Where $\sigma_{c}$, and $\sigma_{m}$ are the tensile strength of the composite and the matrix, respectively, $\lambda$ is the relative elongation of the specimen, $n$ is a parameter characterizing the strain hardening tendency of the matrix, which was calculated by the curve fitting procedure, $x_{f}$ is the filler volume fraction, and $B$ an empirical fitting parameter characterizing the quality of the interfacial adhesion, related to filler/matrix interactions and the size of the interface (Pukánszky, 1990). The lower the $B$ value, the worst is the interfacial adhesion. This model was applied to the PHBV-based composites.

As seen in Fig. 8, the model satisfactorily fits the evolution of the tensile strength over the all range of filler contents for SF- and CF-based composites, with B parameters of -2.31 and -1.08 , respectively, and $n$ values of roughly 1 , i.e. limited strain hardening. Considering the negative values of $\mathrm{B}$ for these formulations, this suggests that the reduction of the tensile strength was not only related to filler/matrix interfacial adhesion effects but also to large microscopic and macroscopic defects that drastically favor macro-cracks initiation and propagation. Besides, the intrinsic properties of the PHBV matrix were affected by the presence of fillers and their amount, which cannot be considered in the model. Indeed, the intrinsic properties of the degraded polymer matrix within a composite material are difficult to approach. It is worth mentioning that a low but positive value of $B$ was obtained for the PHBV-PF formulation ( $\mathrm{B}=0.23)$, meaning that for the PF filler, the 


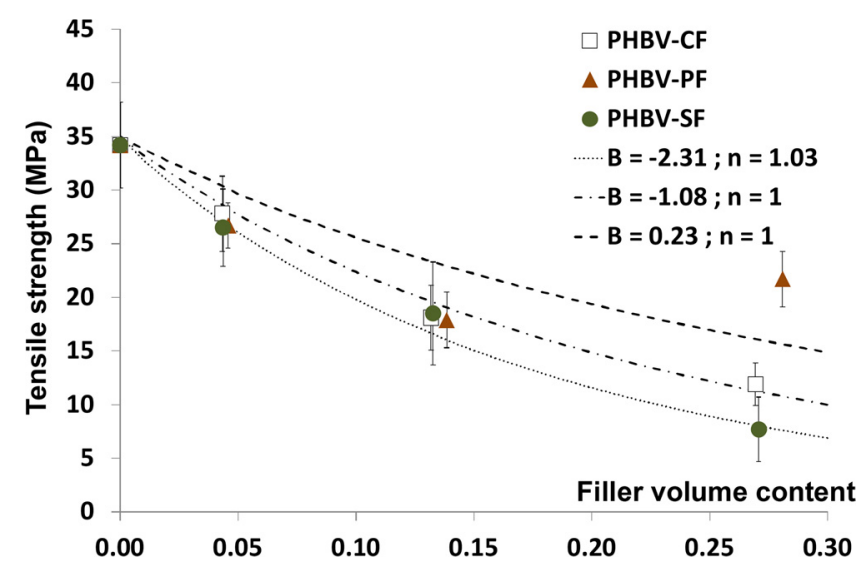

Fig. 8. Experimental values of the stress at break of PHBV and PBHV-based composites filled with 5, 15 and $30 \mathrm{wt} \%$ of CF $(\square)$, SF ( $)$ or PF ( $\boldsymbol{\Delta}$ ) fillers and resulting fitted curves with Pukanszky's model.

negative effect of polymer degradation, and defects could be counterbalanced by the positive effect of a better interfacial adhesion and higher degree of crystallinity. Concluding, the creation of favorable filler/matrix physico-chemical interactions (i.e. higher work of adhesion) appear as a key for the control of the ultimate mechanical properties of such biocomposite systems in which the aspect ratio of the fillers and the resulting size of filler/matrix interfaces are low.

\subsubsection{Water vapour and oxygen permeability}

Results revealed that water vapour permeability WVP strongly depended on the concentration and the nature of the filler (Table 5). Globally, the introduction of CF or SF fillers (except for the PHBV-SF (5\%) formulation) led to a significant increase in WVP of either PP or PHBV. As measured for PHBV-based materials, this increase in WVP was more pronounced for increasing filler contents. WVP increased from $0.9 \times 10^{-12} \mathrm{~mol} \mathrm{~m}^{-1} \mathrm{~s}^{-1} \mathrm{~Pa}^{-1}$ for the neat PHBV up 1.1, 1.5 and $15.1 \times 10^{-12} \mathrm{~mol} \mathrm{~m}^{-1} \mathrm{~s}^{-1} \mathrm{~Pa}^{-1}$ for PHBV-CF(5\%), PHBV-CF(15\%) and PHBV-CF(30\%) respectively, which corresponded to increases of respectively $22 \%, 67 \%$ and more than $1500 \%$. The WVP increase was in the same range for PP, with an increase of $83 \%$ for PP-CF (15\%). In contrast, the introduction of pulp-rich particles in PHBV led to a reduction in WVP of about $44 \%$ for PHBV-PF(5\%) and $22 \%$ for PHBV-PF (15\%), while WVP value remained constant for a high filler content of $30 \mathrm{wt} \%$. In the case of PP, WVP was not significantly impacted by the introduction of $\mathrm{PF}$ fillers.

As already reported for PHBV/wheat straw fibres biocomposites, this was mainly ascribed to the hydrophilic character of fillers (Berthet et al., 2015; Hassaini et al., 2017) and the existence of water vapor clustering (Wolf et al., 2016). It is sure that the presence of interfacial gaps would have an effect on WVP, but this effect is not yet well understood. Indeed, the assumption of Berthet et al. (2015), that a bad filler/matrix interfacial adhesion would favor the creation of a preferential pathway for the diffusion of water vapour is in contradiction with the decrease in diffusivity showed by Wolf et al. (2016). In this study, the very high WVP (increase of a factor of about 25) recorded for PHBV-CF (30\%) was ascribed to the presence of cracks on the surface of films. As already observed by Berthet et al. (2015), the incorporation of lignocellulosic fillers (at a filler content of $20 \mathrm{wt} \%$ ) on WVP of PHBV had not the same impact according to the nature of the filler. Wheat straw fillers led to a significant increase in WVP of PHBV, whereas the introduction of olive mills led to a decrease in WVP. The barrier effect brought by the introduction of PF fillers could be attributed to the apolar nature of this lignin-rich filler, and overall to the better interfacial interactions between PF fillers and PHBV, inducing a tortuosity effect and hence an increase in the water vapor diffusion pathway. The tortuosity effect could also be ascribed to the previously mentioned higher degree of crystallinity (Table 4), PHBV crystallites being less permeable to water vapor.

In the case of food packaging, the large variety of food products to be packaged requires a wide range of mass transfer properties (Petersen et al., 1999). As an example, respiring food products, would require permeable packaging materials to avoid condensation of water vapor inside the packaging, while dry products such as bakery or delicatessen would need barrier packaging materials (Siracusa et al., 2008). Consequently, olive stone (SF)-based composites appeared as promising materials to reach the requirements of respiring food products such as cheese, fruits and vegetable because of their transpiration, whereas olive pulp (PF)-based composites would be more adapted for water sensitive products like sandwiches (Petersen et al., 1999).

Based on tensile properties and WVP results, materials filled with $15 \mathrm{wt} \%$ of olive pomace-based particles were selected for measuring oxygen permeability (Table 5). Hassaini et al. (2017) reported a significant decrease in the oxygen barrier properties after the incorporation of stone-based filler to PHBV. According to these authors, the noncompatibility of the system filler/matrix leads to the formation of micro-voids due to the poor interfacial adhesion between the two components, which make oxygen permeation easier. In this study, oxygen permeability of either PP or PHBV was not significantly impacted by the incorporation of olive pomace-based fillers. These results could be explained by two concomitant and competitive phenomena. Structural changes of PHBV matrix that would be in favor of an increase of oxygen permeability (effect on diffusion, as shown for water vapor) are compensated by the fact that oxygen is an apolar molecule displaying a poor affinity towards lignocellulosic particles (effect on sorption). Only a very slight increase in oxygen permeability (raise of $11 \%)$ was noticed in the case of PHBV-PF (15\%), probably due to the higher apolar character of pulp-rich fractions, and thus higher affinity towards oxygen.

\section{Conclusion}

In response to the ecological concerns aimed at stimulating the development of new materials from renewable sources without competition with food usage, olive pomace, the solid lignocellulosic residue of olive oil extraction, was processed by dry fractionation so as to obtain contrasted fillers for the formulation of petroleum-based (PP) and fully bio-based and biodegradable (PHBV) composites materials.

Our results evidenced that OP-based fillers displayed different affinities towards PP and PHBV matrices depending on their dry fractionation route. Such observations were confirmed by contact angle measurements and SEM analysis. Filler/matrix adhesion had a preponderant impact as regards the functional properties of biocomposites. An appropriate choice of the filler-matrix combination could thus allow modulating the biocomposites properties according to the requirements of the targeted application.

In general, the incorporation of olive pomace fillers resulted in a reduction of both the stress and the elongation at break for either PP and PHBV-based biocomposites. This effect was more pronounced at high filler content. A better preservation of mechanical characteristics was achieved in the case of pulp-rich filler (PF), due to better filler/ matrix interactions and hence higher interfacial adhesion. It is worth noting that mechanical properties were less preserved in the case of PHBV-based composites, probably due to the thermal degradation of PHBV occurring during melt extrusion and thermocompression and favored by the presence of lignocellulosic fillers. Considering the barrier characteristics of the biocomposites, water vapour permeability was increased in presence of SF and CF fillers for both PP and PHBV formulations. Our results suggested that according to their biochemical composition and physicochemical characteristics, OP-based fillers could be used in packaging materials for various types of food products, from fresh respiring products such as cheeses, fruits or vegetables until the water sensitive products like dry or fatty foods and prepared meals. 
According to Zeman and Kubik (2007), the absolute barrier does not exist since it is necessary to adapt barrier properties to the real life.

Finally, the combination of OP-based fillers with thermoplastic polymers to develop low cost and functional biocomposite materials appeared as a relevant and sustainable approach to value one of the main by-products of olive oil industry. Given that PP is the most widely used polymer in the packaging sector, PP/OP-based composites have the advantage of being less expensive than virgin PP materials, with an overall reduced fossil resource content. Concerning PHBV-based biocomposites, the additional huge advantage is that they are fully biobased and biodegradable even in non-composting conditions.

\section{Acknowledgments}

This research was supported by MALICE project co-financed by the European Regional Development Fund, and the PNE Program (2016-2017) of the Algerian Ministry of Higher Education and Scientific Research. Authors would like to thank Benjamin GALLARD from C2MA (IMT Mines Alès) for his technical support in the preparation of the compounds and Amélie BREYSSE from IATE (MontpellierFrance) for her help with image analysis.

\section{References}

ASTM Standard F 1927-07, 2007. Standard Test Method for Determination of Oxygen Gas Transmission Rate, Permeability and Permeance at Controlled Relative Humidity Through Barrier Materials Using a Colorimetric Detector. ASTM International, West Conshohocken, PA.

Angellier-Coussy, H., Gastaldi, E., Gontard, N., Guillard, V., 2011. Influence of processing temperature on the water vapour transport properties of wheat gluten based agromaterials. Ind. Crops Prod. 33, 457-461.

Angellier-Coussy, H., Guillard, V., Guillaume, C., Gontard, N., 2013. Role of packaging in a smorgasbord of action for sustainable food consumption. Agro-Food Ind. High-Tech 24 (3), 15-19.

Ayrilmis, N., Buyuksari, U., 2010. Utilization of olive mill sludge in manufacture of lignocellulosic/polypropylene composite. J. Mater. Sci. 45, 1336-1342.

Barakat, A., De Vries, H., Rouau, X., 2013. Dry fractionation process as an important step in current and future lignocellulose biorefineries: a review. Bioresour. Technol. 134, 362-373.

Barakat, A., Chuetor, S., Monlau, F., Solhy, A., Rouau, X., 2014. Eco-friendly dry chemomechanical pretreatments of lignocellulosic biomass: impact on energy and yield of the enzymatic hydrolysis. Appl. Energy 113, 97-105.

Barham, P.J., Keller, A., Otun, E.L., Holmes, P.A., 1984. Crystallization and morphology of a bacterial thermoplastic: poly-3-hydroxybutyrate. J. Mater. Sci. 19, 2781-2794.

Berthet, M.A., Angellier-Coussy, H., Machado, D., Hilliou, L., Staebler, A., Vicente, A., Gontard, N., 2015. Exploring the potentialities of using lignocellulosic fibers derived from three food by-products as constituents of biocomposites for food packaging. Ind. Crops Prod. 69, 110-122.

Berthet, M.A., Angellier-Coussy, H., Guillard, V., Gontard, N., 2016. Vegetal fibre-based biocomposites: which stakes for food packaging applications. J. Appl. Polym. Sci. 133 (2) SI (42528).

Berthet, M.A., Mayer-Laigle, C., Rouau, X., Gontard, N., Angellier-Coussy, H., 2017. Sorting natural fibres: a way to better understand the role of fibre size polydispersity on the mechanical properties of biocomposites. Compos. Part A 95, 12-21.

Commission Internationale de l'Eclairage (CIE). 2004. Technichal repport-Colorimetry. 3rd Edition. ISBN 3901906339.

Calabia, B.P., Ninomiya, F., Yagi, H., Oishi, A., Taguchi, K., Kunioka, M., Funabashi, M., 2013. Biodegradable poly(butylene succinate) composites reinforced by cotton fiber with silane coupling agent. Polymer 5, 128-141.

Djidjelli, H., Benachour, D., Boukerrou1 A. Zefouni, O., Martinez-Véga, J., Farenc, J., Kaci, M., 2007. Thermal: dielectric and mechanical study of poly (vinyl chloride)/ olive pomace composites. Express Polym. Lett. 1, 846-852.

Fuentes, C.A., Brughmans, G., Tran, L.Q.N., Dupont-Gillain, C., Verpoest, I., Van Vuure, A.W., 2015. Mechanical behaviour and practical adhesion at a bamboo composite interface: physical adhesion and mechanical interlocking. Compos. Sci. Technol. 109, $40-47$.

Gharbi, A., Bel Hassen, R., Boufi, S., 2014. Composite materials from unsaturated polyester resin and olive nuts residue: the effect of silane treatment. Ind. Crops Prod. $62,491-498$.

Hammoui, Y., Molina-Boisseau, S., Duval, A., Djerrada, N., Adjeroud, N., Remini, H., Dahmoune, F., Madani, K., 2015. Preparation of plasticized wheat gluten/olive pomace powder biocomposite: effect of powder content and chemical modifications. Mater. Des. 87, 742-749.

Hassaini, L., Kaci, M., Touati, N., Pillin, I., Kervoelen, A., Bruzaud, S., 2017. Valorization of olive husk flour as a filler for biocomposites based on poly(3-hydroxybutyrate-co3-hydroxyvalerate): effects of silane treatment. Polym. Test. 59, 430-440.

Jones, D.B., 1941. Factors for Converting Percentages of Nitrogen in Foods and Feeds into Percentages of Proteins. Circular $N^{\circ} 183$. United States Department of Agriculture, Washington $22 \mathrm{p}$

Koutsomitopoulou, A.F., Bénézet, J.C., Bergeret, A., Papanicolaou, G.C., 2014 Preparation and characterization of olive pit powder as a filler to PLA-matrix biocomposites. Powder Technol. 255, 10-16.

Lammi, S., Barakat, A., Mayer-Laigle, C., Djenane, D., Gontard, N., Angellier-Coussy, H., 2018. Dry fractionation of olive pomace as a sustainable process to produce fillers for biocomposites. Powder Technol. 326, 44-53. http://dx.doi.org/10.1016/j.powtec. 2017.11.060.

Le Digabel, F., Boquillon, N., Dole, P., Monties, B., Averous, L., 2004. Properties of thermoplastic composites based on wheat-straw lignocellulosic fillers. J. Appl. Polym. Sci. 93, 428-436.

Leroy, E., Petit, I., Audic, J.L., Colomines, G., Deterre, R., 2012. Rheological characterization of a thermally unstable bioplastic in injection molding conditions. Polym. Deg. Stab. 97 (10), 1915-1921.

Martino, L., Berthet, M.A., Angellier-Coussy, H., Gontard, N., 2015. Understanding external plasticization of melt extruded PHBV-wheat straw fibers biodegradable composites for food packaging. J. Appl. Polym. Sci. 132, 10 Article number: 41611.

Maymone, B., Battaglini, A., Tiberio, M., 1961. Ricerche sul valore nutritivo della sansa d'olive. Alimentazione Anim. 4, 219-250.

Monasse, B., Haudin, J.M., 1985. Growth transition and morphology change in polypropylene. Colloid Polym. Sci. 263, 822-831.

Montano-Leyva, B., Ghizzi Da Silva, G., Gastaldi, E., Torres-Chávez, P., Gontard, N., Angellier-Coussy, H., 2013. Biocomposites from wheat proteins and fibers: structure/ mechanical properties relationships. Ind. Crops Prod. 43, 545-555.

Naghmouchi, I., Mutjé, P., Boufi, S., 2015. Olive stones flour as reinforcement in polypropylene composites: a step forward in the valorization of the solid waste from the olive oil industry. Ind. Crops Prod. 72, 183-191.

Nicholson, D.J., Leavitt, A.T., Francis, R.C., 2014. A three-stage klason method for more accurate determinations of hardwood lignin content. Cellulose Chem. Technol. 48 (1-2), 53-59.

Owens, D.K., Wendt, R.C., 1969. Estimation of the surface free energy of polymers. J. Appl. Polym. Sci. 13, 1741-1747.

Ozveren, U., Ozdogan, Z.S., 2013. Investigation of the slow pyrolysis kinetics of olive oil pomace using thermo-gravimetric analysis coupled with mass spectrometry. Biomass Bioenergy 58, 168-179.

Petersen, K., Nielsen, P.V., Bertelsen, G., Lawther, M., Olsen, M.B., Nilsson, N.H., Mortensen, G., 1999. Potential of biobased materials for food packaging. Trends Food Sci. Technol. 10, 52-68.

Plastics-the Facts 2016. An analysis of European plastics production, demand and waste data. www.plasticseurope.org.

Pukánszky, B., 1990. Influence of interface interaction on the ultimate tensile properties of polymer composites. Composites 21 (3), 255-262.

Ravindran, R., Jaiswal, A.K., 2016. Exploitation of food industry waste for high-value products. Trends Biotechnol. 34, 58-69.

Reddy, C.S.K., Ghai, R., Rashmi Kalia, V.C., 2003. Polyhydroxyalkanoates: an overview. Bioresour. Technol. 87, 137-146.

Rigane, G., Bouaziz, M., Sayadi, S., Ben Salem, R., 2012. Identification and characterization of a new iridoid compound from two-phase Chemlali olive pomace. Eur. Food Res. Technol. 234, 1049-1054.

Rodríguez-Gutierrez, G., Rubio-Senent, F., Lama-Munoz, A., García, A., FernandezBolanos, J., 2014. Properties of lignin, cellulose, and hemicelluloses isolated from olive cake and olive stones: binding of water, oil, bile acids, and glucose. J. Agric. Food Chem. 62 (36), 8973-8981.

Romani, V.P., Prentice-Hernández, C., Martins, V.G., 2017. Active and sustainable materials from rice starch, fish protein and oregano essential oil for food packaging. Ind. Crops Prod. 97, 268-274.

Shafizadeh, F., Mcginnis, G.D., Philpot, C.W., 1972. Thermal degradation of xylan and related model compounds. Carbohydr. Res. 25, 23-33.

Siracusa, G., La Rosa, A.D., Siracusa, V., Trovato, M., 2001. Eco-compatible use of olive husk as filler in thermoplastic composites. J. Polym. Environ. 9, 157-161.

Siracusa, V., Rocculi, P., Romani, S., Dalla Rosa, M., 2008. Biodegradable polymers for food packaging: a review. Trends Food Sci. Technol. 19, 634-643.

Tejado, A., Kortaberria, G., Pen, C., Labidi, J., Echeverría, J.M., Mondragon, I., 2007. Lignins for phenol replacement in novolac-type phenolic formulations, Part I: lignophenolic resins synthesis and characterization. J. Appl. Polym. Sci. 106, 2313-2319.

Tran, L.Q.N., Fuentes, C.A., Dupont-Gillain, C., Van Vuure, A.W., Verpoest, I., 2013. Understanding the interfacial compatibility and adhesion of natural coir fibre thermoplastic composites. Compos. Sci. Technol. 80, 23-30.

Wolf, C., Guillard, V., Angellier-Coussy, H., Ghizzi Da Silva, G., Gontard, N., 2016. Water vapour sorption and diffusion in wheat straw particles and impact on mass transfer properties of biocomposites. J. Appl. Polym. Sci. 133 (16) article number 43329.

Yang, H., Yan, R., Chen, H., Lee, D.H., Zheng, C., 2007. Characteristics of hemicellulose, cellulose and lignin pyrolysis. Fuel 86, 1781-1788.

Zeman, S., Kubik, L., 2007. Permeability of polymeric packaging materials. Tech. Sci. 10, 27-34. 